Quim. Nova, Vol. 34, No. 7, 1242-1254, 2011

\title{
DO ENGENHO À BIORREFINARIA. A USINA DE AÇÚCAR COMO EMPREENDIMENTO INDUSTRIAL PARA A GERAÇÃO DE PRODUTOS BIOQUÍMICOS E BIOCOMBUSTÍVEIS
}

\author{
José Augusto R. Rodrigues \\ Instituto de Química, Universidade de Campinas, CP 6154, 13093-971 Campinas - SP, Brasil
}

Recebido em 1/11/10; aceito em 16/2/11; publicado na web em 5/5/11

\begin{abstract}
FROM THE MILL TO A BIOREFINERY. THE SUGAR FACTORY AS AN INDUSTRIAL ENTERPRISE FOR THE GENERATION OF BIOCHEMICALS AND BIOFUELS. A sugar cane mill is at the present moment a modest biorefinery producing few products such as sugar, ethanol and polyhydroxybutyrate (PHB). In the near future, this mill can expand its production using several renewable feedstock's to produce biofuels and high value biobased chemicals. However, the choice of appropriate products for addition to the portfolio is challenged by a lack of broad-based conversion technology coupled with a plethora of potential targets. The intent of this revision was to catalyze research efforts to expand the list of products and to present an updated evaluation of potential target structures for chemical production.
\end{abstract}

Keywords: biorefinery; biotechonology; sustainable chemistry.

\section{INTRODUÇÃO}

No início o engenho brasileiro produzia apenas açúcar mascavo, tendo como subproduto a cachaça. Nestes cinco séculos, este pequeno empreendimento rural evoluiu para usinas de açúcar e álcool produzindo diversas nomenclaturas de açúcar, demerara, cristal, refinado e "orgânico", além do polímero PHB (poli-hidroxibutirato) e de energia elétrica. $\mathrm{O}$ engenho ainda continua operando, agora gerando a cachaça artesanal, sendo que os maiores fazem a água ardente, a terceira bebida destilada mais consumida no planeta. Nesta resenha, avalia-se qual será a evolução que pode ser esperada para a usina de açúcar e álcool como um empreendimento industrial para geração de produtos químicos.

Desde a época do descobrimento, o açúcar tem sido fundamental para a economia do Brasil, naquela época o produto mundial manufaturado mais valioso. ${ }^{1} \mathrm{O}$ PIB do setor sucroenergético foi de US\$28.2 bilhões, equivalente a quase $2 \%$ do PIB brasileiro (taxa de câmbio de $\mathrm{R} \$ 1,84$ por dólar, a média de 2008). ${ }^{2}$ Os principais produtos do setor no mercado interno e externo foram: etanol hidratado, etanol anidro, etanol não-combustível, açúcar, bioeletricidade, levedura e crédito de carbono. A safra 2008/09 de cana-de-açúcar, de 568,9 milhões de toneladas foi cultivada em área plantada de 8,5 milhões de hectares. Nos melhores cultivos da região Centro-Sul brasileira, a produtividade foi da ordem de 85 toneladas de cana por hectare. ${ }^{3}$ A matriz energética brasileira, que se destaca pela grande incidência de fontes renováveis, passou por transformações que a colocaram entre as mais limpas do mundo. Nesta década, caracterizada pela introdução dos carros flexíveis, a participação do petróleo e derivados na matriz diminuiu cerca de 8 pontos percentuais: passou de $45,5 \%$ em 2000 para $37,9 \%$ em 2009. Ao fim desse período, cerca de $18 \%$ da energia consumida no país já provinha de derivados da cana-deaçúcar, ultrapassando a energia hidráulica em importância na matriz e assumindo o segundo lugar. ${ }^{4}$

A cadeia sucroenergética vem mostrando seu potencial de suprir produtos de maneira sustentável, o que contribui para que o Brasil

\footnotetext{
*e-mail: jaugusto@iqm.unicamp.br
}

tenha uma excelente imagem de produtor de energia verde. Estima-se que, em 2015, 80\% do combustível consumido no país seja etanol. A bioeletricidade, gerada pela queima do bagaço de cana, apresenta potencial de suprir cerca de $15 \%$ de toda a demanda de eletricidade do país até o final da década. O país caminha para dominar a exportação mundial de açúcar, com quase 50\% do mercado mundial em 2009 e expectativas de se atingir mais de $60 \%$ em cinco anos.

O veículo flex., lançado em 2003 e que hoje responde por cerca de $90 \%$ das vendas, é o ponto alto da história do sucesso do etanol brasileiro nesta década. Isso não significa que não possa ser melhorado com ganhos de eficiência energética e desempenho ambiental. Ao contrário, com a adoção das necessárias políticas públicas, há espaço para sensíveis avanços tecnológicos. A produção mundial de biocombustíveis é crescente, somando, em 2008, cerca de 80 bilhões de litros, dos quais 67 bilhões de etanol. Entre 2000 e 2008, a oferta de etanol aumentou 18,6\% ao ano e a de biodiesel 37,3\% (Tabela 1). Trata-se de um mercado cujos produtores mais importantes de etanol são os Estados Unidos (34 bilhões de litros em 2008) e o Brasil (27 bilhões), ambos os países respondendo por cerca de $90 \%$ da produção mundial. Somando a produção mundial de etanol com os 12 milhões de litros de biodiesel, resulta um volume equivalente a 900 mil barris/dia de petróleo correspondendo a 1,1\% da produção mundial do combustível fóssil.

Em fevereiro de 2010, a Environmental Protection Agency (EPA), dos Estados Unidos, designou o etanol de cana-de-açúcar como biocombustível avançado, capaz de reduzir as emissões de gases do efeito estufa (GEE) em pelo menos $61 \%$ em comparação com a gasolina. Para serem classificados como combustível renovável, biocombustível avançado, biocombustível celulósico ou biodiesel de biomassa, os combustíveis devem atingir percentuais mínimos de redução de emissões de GEE ao longo de seus ciclos de vida em comparação com as emissões da gasolina e do diesel. ${ }^{6}$

Várias são as justificativas para a classificação do etanol brasileiro de cana-de-açúcar como biocombustível avançado. Vai desde a elevada produtividade agrícola, às centenas de variedades de cana à disposição do agricultor, que conta com variedades específicas para cada variedade de solo e de microclima. A posição de terras aráveis 
Tabela 1. Produção de etanol no Brasil em milhões de litros ${ }^{5}$

\begin{tabular}{|c|c|c|c|c|c|}
\hline Safra & 2004-05 & 2005-06 & 2006-07 & 2007-08 & $2008-09$ \\
\hline Etanol anidro combustível & 7.689 & 7.352 & 5.128 & 6.354 & 6.406 \\
\hline Etanol hidratado combustível & 5.118 & 5.973 & 7.696 & 10.964 & 13.821 \\
\hline Etanol exportado & 2.631 & 2.526 & 3.928 & 3.518 & 5.228 \\
\hline Etanol total para outros fins & 703 & 708 & 729 & 686 & 1.166 \\
\hline Total & 16.141 & 16.559 & 17.481 & 21.522 & 26.621 \\
\hline
\end{tabular}

de qualidade adequada abaixo do Equador até ao Trópico de Capricórnio, ensolarada durante a maior parte do ano, propicia à cana ter um dos melhores aproveitamentos fotossintéticos entre as gramíneas, resultando um elevado rendimento na produção de sacarose. É nesta região tropical do Sudeste onde se situa a região mais desenvolvida, mais populosa do país e junto aos maiores consumidores do etanol. A indústria canavieira dispõe nesta região de Universidades e centros de pesquisa que há muito vêm dando suporte ao setor. A USP com institutos de ensino e pesquisa em Piracicaba, São Carlos e Ribeirão Preto, a UNICAMP, a UNESP e a UFSCar juntamente com o Centro de Tecnologia Canavieira (CTC) e Instituto Agronômico de Campinas (IAC), vêm ao longo de muitos anos formando profissionais e dando apoio tecnológico ao setor sucroalcooleiro. ${ }^{7}$

Foi após a criação do Programa Nacional do Álcool (PROÁLCOOL) em 1974 pelo Governo Federal, que o etanol passou a receber atenção dos usineiros como mais um produto além do açúcar. $\mathrm{O}$ etanol é uma necessidade para a usina já que não é econômico extrair todo o açúcar contido no caldo de cana. Com as águas mães da cristalização, o melaço, a usina realiza a fermentação e, deste modo, aproveita todo o açúcar contido na planta. Após a esterilização do caldo ou do melaço, a fermentação é realizada com a levedura Saccharomyces cerevisiae (o popular fermento de padaria) tendo uma concentração de sacarose em torno de 200 $\mathrm{g} \mathrm{L}^{-1}$ em dornas enormes de 100 a 1000 mil L de volume total. ${ }^{8}$ Após cerca de 12 h de reação obtém-se um teor alcoólico inferior a $100 \mathrm{~g} \mathrm{~L}^{-1}$ que é enviado para a unidade de destilação, resultando o etanol absoluto $(95,5 \%)$ ou o anidro com teor de álcool de no mínimo 99,7\%. A levedura é separada do fermentado (chamado de vinho) por centrifugação e reciclada para uma nova fermentação após o tratamento com ácido sulfúrico concentrado, neutralização e determinação da contaminação microbiológica. A contaminação por leveduras selvagens e bactérias é elevada e há necessidade de combatê-las constantemente com antibióticos antes da reutilização em novo ciclo fermentativo (Figura 1).

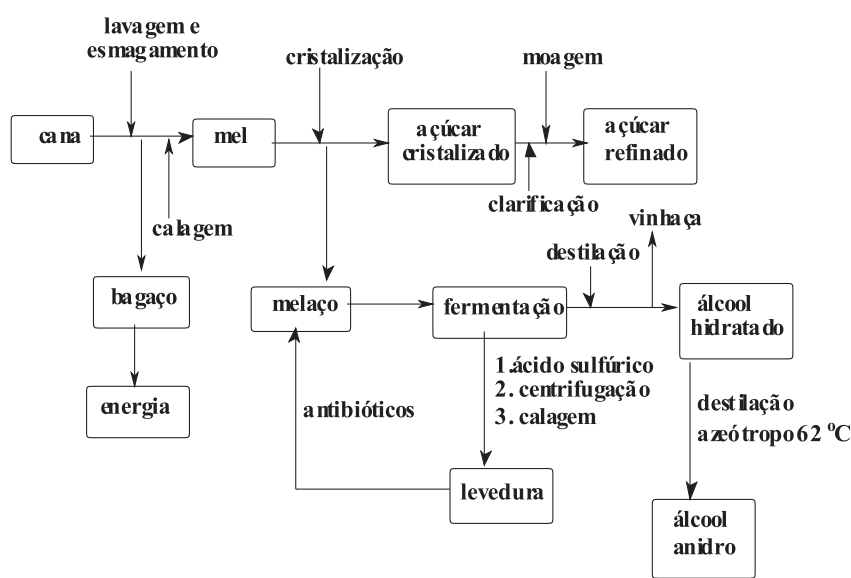

Figura 1. Esquema simplificado da transformação da cana-de-açúcar em açúcar e etanol
Resumidamente, a reação de fermentação pode ser representada conforme o Esquema 1 - para cada molécula de sacarose são produzidos 4 moles de etanol e 4 moles de gás carbônico. A energia necessária para efetuar principalmente a moagem da cana-de-açúcar, nas centrífugas e na etapa da destilação, é fornecida pela queima do bagaço nas caldeiras da usina. Nas usinas mais eficientes, esta queima do bagaço gera saldo positivo de energia, que é convertida em energia elétrica e vendida para as concessionárias de eletricidade.

$$
\begin{array}{lll}
\mathrm{C}_{12} \mathrm{H}_{22} \mathrm{O}_{11} \longrightarrow & 2 \mathrm{C}_{6} \mathrm{H}_{12} \mathrm{O}_{6} \longrightarrow & 4 \mathrm{C}_{2} \mathrm{H}_{5} \mathrm{OH}+4 \mathrm{CO}_{2} \\
\text { sacarose } & \text { glicose }+ \text { frutose } & \text { etanol }
\end{array}
$$

Esquema 1. A reação global da fermentação da sacarose em etanol e gás carbônico

A produção de uma típica usina brasileira de açúcar, álcool e bagaço é apresentada na Figura 2. O açúcar é utilizado como alimento no varejo e no atacado pela indústria alimentícia. $\mathrm{O}$ etanol é comercializado como combustível de veículos de transportes, pela indústria de bebidas e de cosméticos. O bagaço de cana é usado para gerar energia para a própria usina e a sobra vendida para as concessionárias de eletricidade. A sobra de fermento é vendida para a indústria de ração animal. Entretanto, a usina perde gás carbônico, como mostrado no Esquema 1, que poderá ser transformado em metanol e será posteriormente motivo de discussão.

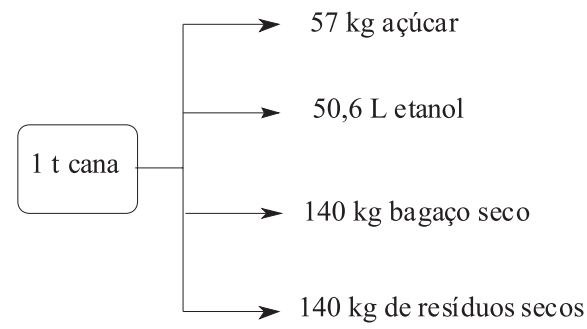

Figura 2. Produção de uma típica usina de açúcar e etanol no Brasil ${ }^{9}$. Adaptada da ref. 9.

No início da década de 1980, o governo militar incentivava a substituição de produtos derivados do petróleo, muito escasso no Brasil de então e de custo elevado após a primeira grande crise de meados da década anterior. A indústria buscou no etanol uma fonte para substituir alguns produtos derivados do petróleo, incentivada pela política nacional da alcoolquímica. Algumas empresas de porte desenvolveram produtos como acetato de etila, ácido acético, anidrido acético, butanol, etc., tendo o etanol como fonte primária. Com a diminuição do preço de petróleo no mercado internacional durante a década de 1990, o interesse pela alcoolquímica arrefeceu. No inicio do novo século, as usinas de açúcar e álcool começaram a crescer em número, adquirindo um estágio de maior competitividade. Foi nesta época que a Usina da Pedra em Altinópolis, SP, iniciou a produção do polímero biodegradável poli-hidroxibutirato (PHB), em bateladas de $500 \mathrm{~kg}$, a partir da transformação de sacarose e ácido propiônico 
sob a ação de uma bactéria. O PHB parece indicar para as usinas que a sacarose poderia ser uma fonte renovável de matéria-prima para substituir produtos de origem fóssil e de existência finita, e uma oportunidade para a expansão dos negócios.

\section{O DESAFIO DE A BIOMASSA SUBSTITUIR O PETRÓLEO: O CONCEITO DE BIORREFINARIA}

Atualmente, as necessidades energéticas do planeta são baseadas principalmente nos combustíveis fósseis. As reservas destes depósitos são finitas e a sua exploração tem causado sérios problemas ambientais, tais como o efeito estufa causado pela queima dos gases e graves acidentes como o ocorrido na recente (abril de 2010) explosão da plataforma da BP no Golfo do México. Em decorrência, a procura por fontes alternativas renováveis tem se intensificado para suprir o constante aumento da demanda energética e de matéria-prima. Uma das poucas fontes que tem potencial para atender a estes desafios de sustentabilidade é a biomassa, que aparenta ser a única alternativa viável frente aos recursos fósseis para a produção de combustíveis de transportes e de produtos químicos, já que é o único material rico em carbono disponível no planeta, além dos fósseis. Em decorrência, tem sido proposto um complexo fabril similar ao de uma refinaria de petróleo e que vem sendo chamado de "biorrefinaria" para produzir produtos químicos e energia a partir de biomassa. Entende-se por biorrefinaria uma unidade industrial com facilidades capazes de converter biomassa em produtos químicos e combustíveis. ${ }^{10}$ Para atingir estes objetivos de desenvolvimento sustentável, as biorrefinarias devem exercer um papel dominante neste atual milênio. ${ }^{11}$

A biomassa é formada por carboidratos, lignina, proteínas, gorduras e numa menor extensão, por várias outras substâncias, tais como vitaminas, terpenos, carotenoides, alcaloides, pigmentos e flavorizantes. O objetivo de uma biorrefinaria é transformar estes materiais abundantes em produtos úteis através de uma combinação de tecnologias e processos.

Atualmente, os combustíveis baseados em biomassa usados em transportes, ou seja, biocombustíveis, são identificados como biocombustíveis de primeira e de segunda geração. Os de primeira geração são aqueles produzidos a partir de matérias-primas usados também como alimentos, para humanos e animais. Em decorrência, estes biocombustíveis geram questionamentos éticos, políticos e ambientais. Para contornar estas inquietações, a produção de biocombustíveis de segunda geração (isto é, gerados a partir de resíduos, rejeitos ou de produtos não comestíveis), vem ganhando crescente interesse nos anos recentes como uma possível alternativa mais verde do que os combustíveis fósseis. Com o desenvolvimento de combustíveis de segunda geração, esperase que o uso de biomassa em complexos da biorrefinaria assegure um benefício ambiental adicional e dê maior segurança energética, graças à coprodução tanto de bioenergia como de produtos químicos mais valiosos. Na Figura 3, é feita uma comparação resumida entre os combustíveis fósseis, de primeira e de segunda geração.

\section{Combustíveis de primeira geração}

Os combustíveis de primeira geração são produzidos a partir de açúcar, amido, óleo vegetal ou gordura animal usando tecnologias convencionais. As fontes básicas são frequentemente sementes e grãos, tais como trigo, milho e soja. Os combustíveis de primeira geração mais comuns são bioetanol, biodiesel e biogás derivado de amido.

O bioetanol é obtido de fontes de biomassa tais como cana-deaçúcar, beterraba doce, milho, trigo e mandioca. Os Estados Unidos são atualmente o maior produtor de bioetanol obtido a partir de milho (de custo três vezes superior ao do derivado de cana-de-açúcar), seguido do Brasil que utiliza cana-de-açúcar. A União Europeia produz

\begin{tabular}{l}
$\begin{array}{l}\text { Fonte Fóssil } \\
\text { Carvão } \\
\left(\mathrm{CO}+\mathrm{H}_{2}\right), \text { Hidrocarbonetos FT } \\
\text { (Fischer-Tropsch) }\end{array}$ \\
$\begin{array}{l}\text { Petróleo } \\
\text { GLP, Ga solina, Nafta, Diesel, Querosene } \\
\text { Problemas: } \\
\text { exaustão da reserva petrolífera } \\
\text { poluição ambiental } \\
\text { dificuldades econômicas e ecológicas }\end{array}$ \\
$\begin{array}{l}\text { Combustível de 1 } \\
\text { a Geração } \\
\text { Fontes: } \\
\text { óleos vegetais, milho, açúcar etc. } \\
\text { Produtos: } \\
\text { biodiesel, etanol de milho e de açúcar } \\
\text { Problemas: } \\
\begin{array}{l}\text { Fontes limitadas (alimento x combustível) } \\
\text { Mistura parcial com combustível }\end{array} \\
\text { Benefícios: } \\
\text { Amigável do ambiente, econômico e } \\
\text { socialmente seguro }\end{array}$ \\
\hline
\end{tabular}

Combustível de $2^{\text {a }}$. Geração
Fontes: não alimentos, baratos, biomassa de
plantas abundantes
Produtos: bio-óleo, óleo FT, lignocelulósico,
etanol, butanol e misturas de alcoóis
Vantagens:
Não competem com alimentos
Tecnologia em desenvolvimento
Amigável do ambiente
Problema:
a tecnologia não está pronta

Figura 3. Comparação de combustíveis fósseis, de primeira e segunda geração

muito menos bioetanol a partir de beterraba doce e batata.

O biodiesel é produzido a partir de cereais tais como girassol, soja, canola e também a partir de óleo de palma e resíduos de óleos comestíveis. A Alemanha é o maior produtor de biodiesel a partir de girassol e canola.

Já o biogás é produzido por digestão anaeróbica de estrumes, gramas, rejeitos agrícolas, orgânicos e em aterros sanitários. Contudo, o biogás e derivados principalmente de resíduos e rejeitos podem ser considerados como combustíveis de segunda geração, pois não têm origem em materiais comestíveis. Nos últimos anos, a produção de biogás tem sido fortemente implementada em países europeus com subsídios econômicos para geração de eletricidade. Na Alemanha e na Suécia, o biogás vem sendo usado como biocombustível automotivo.

As vantagens dos combustíveis de primeira geração são decorrentes do elevado conteúdo de açúcar e de lipídeos das matérias-primas, e à sua fácil conversão em biocombustível. A cadeia de produção de muitos biocombustíveis foi analisada pela Avaliação do Ciclo de Vida 
(LCA, Life Cycle Assessment) para determinar seus desempenhos ambientais. ${ }^{12}$ Muitos estudos de LCA encontraram uma redução nas emissões globais e de consumo de energia fóssil pelos biocombustíveis (bioetanol e biodiesel) que são usados para substituir o diesel e a gasolina. ${ }^{13}$ Os estudos que examinaram estas e outras questões ambientais concluíram que a maioria, mas não todos os biocombustíveis quando substituem os combustíveis fósseis levam à diminuição do impacto no ambiente. ${ }^{14}$

A primeira geração de biocombustíveis está em competição com a indústria de alimentos e de ração pelo uso da biomassa e terra agrícola levantando questões éticas. $\mathrm{O}$ aumento de preços dos combustíveis fósseis aumenta em grande proporção os preços dos cereais e, por conseguinte os dos biocombustíveis. Entretanto, o etanol de canade-açúcar produzido no Brasil é o único biocombustível líquido que parece sofrer menos dos questionamentos anteriores em razão da alta produtividade agrícola. ${ }^{15}$

Em conclusão, os biocombustíveis de primeira geração produzidos atualmente de açúcares, amidos e óleo vegetais causam sérios questionamentos. Estes produtos competem com os alimentos pelas mesmas matérias-primas e por terras férteis, tendo sua potencial disponibilidade limitada pela necessidade de solo fértil. A efetiva economia de emissão de $\mathrm{CO}_{2}$ e o consumo de energia fóssil são limitados pelo alto uso de energia requerida para o cultivo e conversão. ${ }^{16}$ Estas limitações são esperadas serem parcialmente superadas pelo desenvolvimento dos chamados biocombustíveis de segunda geração. ${ }^{17}$

\section{Combustíveis de segunda geração}

Os combustíveis de segunda geração são produzidos a partir de uma ampla variedade de produtos não alimentícios, pelo menos para os humanos. Entre eles estão incluídas as utilizações de materiais lignocelulósicos, tais como resíduos agrícolas, florestais e industriais. Contrariamente aos combustíveis de primeira geração, nos quais são utilizadas frações das plantas, os de segunda geração empregam a planta integral para a produção da bioenergia.

Os biocombustíveis de segunda geração, por exemplo, o diesel Fischer-Tropsch (FT) a partir de biomassa e bioetanol de lignocelulose, prometem vantagens sobre os biocombustíveis de primeira geração em termos de eficiência do uso da terra e desempenho ambiental, segundo a maioria dos estudos publicados. ${ }^{18}$ Devido ao desenvolvimento tecnológico, o desempenho ambiental dos combustíveis de segunda geração pode beneficiar o emprego de elevadas quantidades de resíduos e rejeitos lignocelulósicos que estão atualmente disponíveis. Podem constituir a fonte de matéria-prima principal que também pode ser suplementada com produtos agrícolas não alimentares como gramas e florestas de curta rotação. A maioria dos processos e tecnologias para os biocombustíveis de segunda geração a partir de resíduos de biomassa ainda está num estágio pré-comercial, mas podem entrar no mercado num futuro próximo. ${ }^{19} \mathrm{~A}$ matéria-prima é abundante, barata e facilmente encontrada, o que é um incentivo para seu aproveitamento, permitindo a coprodução de combustíveis valiosos, compostos químicos, eletricidade e calor, conduzindo a produção de energia sustentável com melhores desempenhos ambientais e econômicos, através do desenvolvimento dos conceitos de biorrefinarias. ${ }^{20}$

\section{A MATÉRIA-PRIMA DAS BIORREFINARIAS}

Espera-se que as biorrefinarias se desenvolvam em complexos industriais capazes de revitalizar as áreas rurais. Diferentemente das refinarias de petróleo, que são unidades industriais de elevado porte, as biorrefinarias deverão englobar instalações dos mais variados tamanhos. Muitas delas poderão combinar seu fluxo de material para atingir uma completa utilização de todos os componentes de biomassa. O resíduo de uma bioindústria, como a lignina de uma planta de etanol lignocelulósico, poderá ser aproveitado por outras indústrias próximas formando sistemas integrados. Além disso, como os recursos de biomassas estão disponíveis localmente, o seu aproveitamento pode contribuir para reduzir a dependência de nações da importação de combustíveis fósseis. ${ }^{21}$

A estrutura da biomassa é totalmente diferente daquela usada pela refinaria de petróleo. Diferentemente do petróleo, a composição da biomassa não é homogênea, pois as fontes de biomassa são grãos, madeira, grama e resíduos biológicos contendo carbono, hidrogênio e oxigênio, além de constituintes bem menores formados principalmente por nitrogênio e enxofre. A ampla variedade na composição da biomassa é tanto uma vantagem como uma desvantagem. A vantagem é que as biorrefinarias podem produzir um conjunto maior de classes de produtos do que as refinarias de petróleo, já que são alimentadas por amplas variedades de matérias-primas. A desvantagem é que um número bem maior de processos tecnológicos é necessário, além do que muitos destes processos ainda se encontram em estágio de desenvolvimento. ${ }^{22}$

Para ser empregada na produção de biocombustíveis e produtos químicos (ou bioquímicos), a biomassa exige um pré-tratamento de despolimerização e de desoxigenação. A desoxigenação é necessária porque a presença de oxigênio em biocombustíveis reduz o conteúdo energético e usualmente aumenta sua polaridade, o que dificulta a sua mistura com os atuais combustíveis fósseis. ${ }^{23}$ As aplicações químicas podem exigir uma menor desoxigenação, uma vez que a presença de oxigênio nos produtos frequentemente propicia valiosas propriedades físicas e químicas.

Todos os tipos de biomassa lignocelulósica são constituídos de três componentes primários: celulose, hemicelulose e lignina. A celulose de fórmula $\left(\mathrm{C}_{6} \mathrm{H}_{10} \mathrm{O}_{5}\right)_{n}$ é um polissacarídeo $\mathrm{C} 6$ formado por uma longa cadeia de moléculas de glicose. A hemicelulose de fórmula $\left(\mathrm{C}_{5} \mathrm{H}_{8} \mathrm{O}_{4}\right)_{\mathrm{n}}$ e $\left(\mathrm{C}_{6} \mathrm{H}_{10} \mathrm{O}_{5}\right)$ é um componente relativamente amorfo, que é mais facilmente quebrada quimicamente por calor do que a celulose é constituída por uma mistura de polissacarídeos C6 (galactose e manose) e polissacarídeos C5 (xilose e arabinose). A lignina é essencialmente o cimento que propicia a rigidez estrutural das plantas e árvores, formada por uma rede polimérica tridimensional de unidades metoxilas, arilpropanos e hidroxifenóis. A fórmula empírica deste polímero complexo é $\mathrm{C}_{9} \mathrm{H}_{10} \mathrm{O}_{2}\left(\mathrm{OCH}_{3}\right)_{\mathrm{n}}$ no qual $n$ é a razão de $\mathrm{CH}_{3} \mathrm{O}$ para grupos $\mathrm{C} 9: n=1,4 ; 0,94$ e 1,18 para as madeiras duras, moles e gramíneas, respectivamente. O que dá a rigidez a esta rede polimérica são as ligações cruzadas. A lignina é o maior constituinte não carboidrato, correspondendo entre 15 e $25 \%$ do vegetal.

Diferentes tecnologias são empregadas para a obtenção de produtos químicos e combustíveis a partir dos componentes de biomassa lignocelulósica. A conversão bioquímica é usada para processar os componentes açúcares da celulose e hemicelulose para convertê-los em etanol pela fermentação. ${ }^{24}$ Já a conversão química ${ }^{25}$ através da hidrólise ácida pode levar à produção do ácido levulínico (a partir de polissacarídeos C6) e furfural (a partir de polissacarídeos C5). ${ }^{26}$ O terceiro componente da biomassa lignocelulósica, a lignina, não é fermentável, mas pode ser queimada para gerar eletricidade e calor, ou passar por tratamentos termoquímicos para produzir biocombustíveis (diesel-FT a partir de gás de síntese depois da gaseificação) e produtos químicos (pela pirólise). ${ }^{27}$ Além disso, todos os três componentes principais da biomassa podem ser gaseificados para gás de síntese ou pirolisados para bio-óleo, os quais podem ser transformados para produzir biocombustíveis ou bioquímicos (Figura 4) ${ }^{28}$ Os principais procedimentos empregados na transformação da biomassa lignocelulósica estão resumidos na Figura 5. 


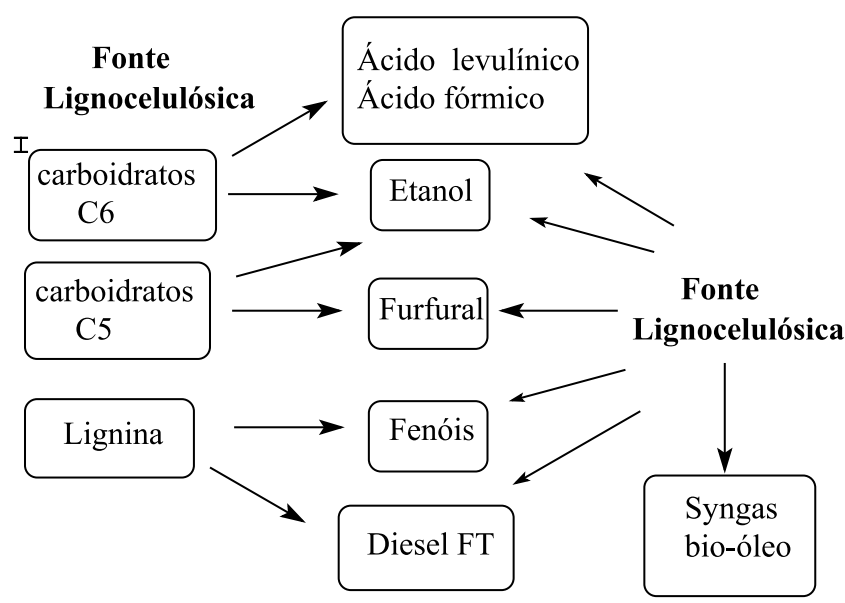

Figura 4. Panorama esquemático para a conversão de biomassa e seus componentes
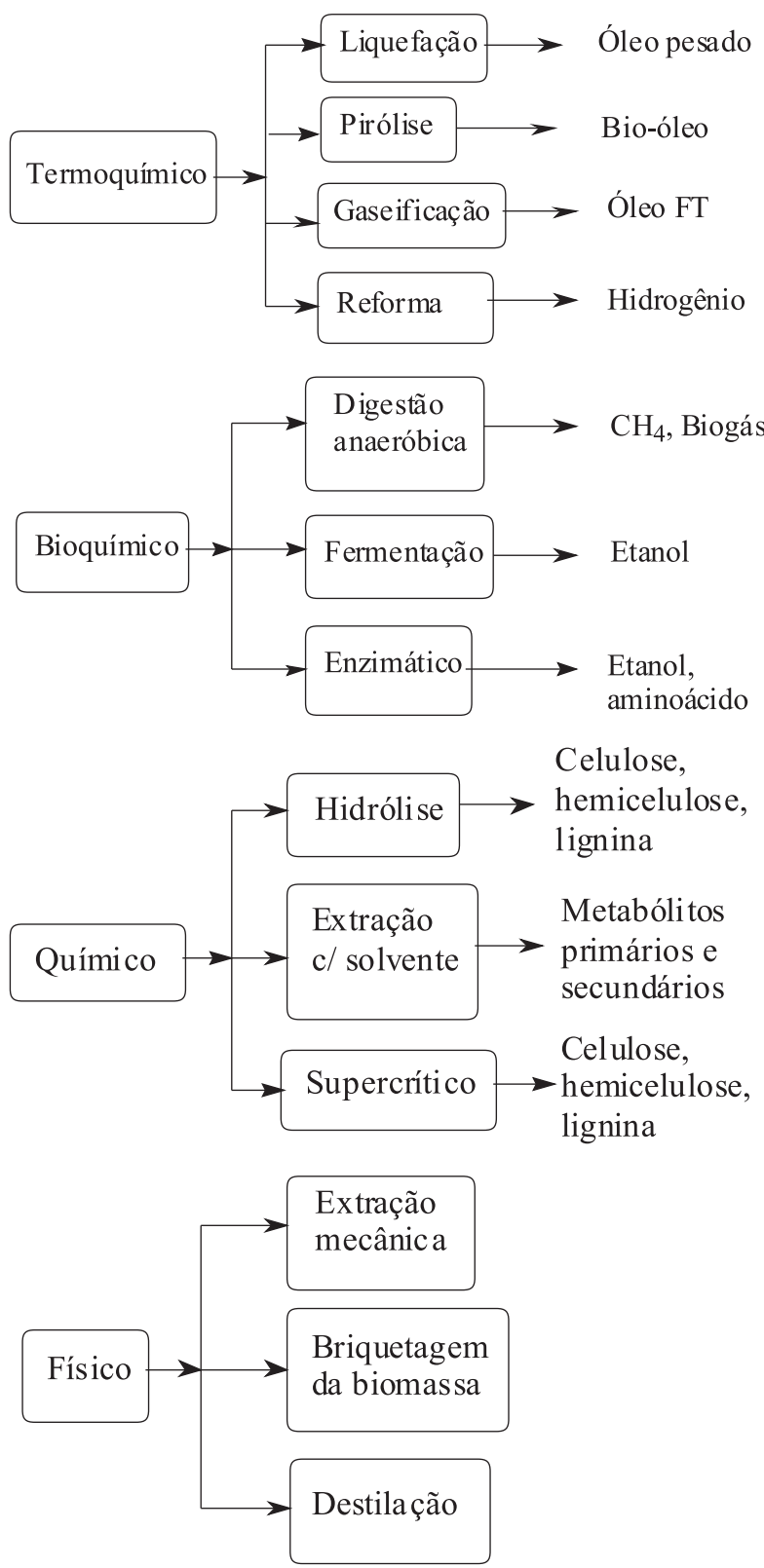

Figura 5. Processos de conversão de biomassa

\section{AS PLATAFORMAS QUÍMICAS ESPERADAS PARA UMA BIORREFINARIA}

Uma indústria centrada na biorrefinaria objetiva produzir produtos químicos em elevados volumes a partir de biomassa, e deverá selecionar diferentes plataformas daquelas correntemente usadas na indústria petroquímica. Em princípio, toda a plataforma de uma refinaria de petróleo pode ser substituída pela biomassa, mas com menor rendimento e altos custos, e espera-se que as futuras biorrefinarias sejam baseadas em um limitado número de alternativas das quais todas as outras especialidades e produtos volumosos possam ser derivados.

Em 2004, uma lista das mais promissoras moléculas da bioplataforma, os blocos de construção dos produtos químicos, foi compilada pelo US Department of Energy com a intenção de que ela desse uma diretriz à pesquisa para que processos fossem direcionados para a sua produção e desenvolvimento. ${ }^{29}$ Alguns produtos, tais como ácido lático, ácido cítrico e etanol, foram omitidos da lista já que a pesquisa de sua produção era considerada se encontrar em um estado avançado (Tabela 2).

Em comparação com as plataformas derivadas de petróleo (etileno, benzeno, etc.), as moléculas das bioplataformas possuem um elevado conteúdo de oxigênio. Isto vai resultar num deslocamento interessante na indústria de procedimentos de oxidação agressivos ao ambiente para uma redução química mais verde; por exemplo, usando hidrogênio sobre um catalisador heterogêneo. Em oposição à adição de funcionalidade, como ocorre normalmente na indústria baseada no petróleo, haverá um deslocamento para moléculas que em grande parte já possuem a desejada funcionalidade ou pré-funcionalidade. ${ }^{30}$

Um exemplo ilustrativo destas plataformas químicas derivadas de biomassa é o ácido levulínico $\left(\mathrm{C}_{5} \mathrm{H}_{8} \mathrm{O}_{3}\right)$, que é formado pela hidrólise ácida de carboidratos $\mathrm{C} 6$ e que pode ser convertido em um amplo número de derivados. A celulose é hidrolisada para carboidratos C6 e então o ácido levulínico é obtido através do hidroximetilfurano intermediário, com uma eficiência de 50\%. O ácido levulínico pode ser convertido a vários produtos, tanto químicos como aditivos de combustíveis (Figura 6). Deste modo pode resultar: ${ }^{31}$ o metiltetraidrofurano (MTHF) é um biocombustível que pode ser misturado com gasolina. É obtido pela desidratação e hidrogenação do ácido levulínico; $\delta$-aminolevulínico é um herbicida obtido por síntese química; ácido difenólico é um polímero produzido pela reação de ácido levulínico com fenóis; levulinato de etila é um aditivo para o diesel.

Os produtos de biorrefinaria podem ser agrupados em duas categorias: produtos, materiais e produtos de energia.

Os produtos de energia mais importantes são: gasosos - biogás, singás, hidrogênio, biometano; sólidos - péletes, lignina, carvão; líquidos - bioetanol, biodiesel, biocombustíveis-FT, bio-óleo.

Os mais importantes produtos químicos e materiais são: químicos - produtos de alta tonelagem, da química fina e blocos de construção sintéticos; ácidos orgânicos - lático, succínico, propiônico, itacônico e outros derivados de açúcar; polímeros e resinas - plásticos derivados de amido, polietileno, polipropileno, polibutadieno, resinas fenólicas, resinas furânicas; biomateriais - derivados da madeira, polpa, papel, celulose; alimentos e ração animal; fertilizantes, cosméticos, fragrâncias.

\section{O PAPEL DA QUÍMICA VERDE}

No estabelecimento da futura produção sustentável destes biocombustíveis e bioquímicos, é absolutamente fundamental a integração da Química Verde com as biorrefinarias através de tecnologias de baixo impacto ambiental. A Química Verde pode ser considerada como uma série de princípios aplicados na manufatura de produtos almejando a eliminação, o uso ou a geração de produtos químicos ambientalmente 
Tabela 2. Lista das 14 plataformas de biomassa, segundo o US Department of Energy

\begin{tabular}{|c|c|c|c|}
\hline Bio-PM & Estrutura & Bio-PM & Estrutura \\
\hline Glicerol & & $(S, R, R)$-xilitol & \\
\hline Ácido 3-hidroxi-propiônico & $\mathrm{O}$ & Ácido glutâmico & \\
\hline Ácido L-aspártico & O & Ácido itacônico & $\mathrm{O}$ \\
\hline Ácido fumárico & $\mathrm{O}$ & Ácido levulínico & $\mathrm{O}$ \\
\hline 3-hidroxi-butirolactona & & Ácido 2,5-furan-di-carboxílico & \\
\hline Ácido málico & $\mathrm{O}$ & Ácido glucárico & \\
\hline Ácido succínico & 0 & sorbitol & \\
\hline
\end{tabular}

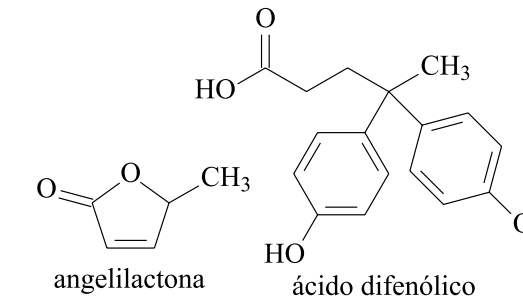<smiles>C=CC(=O)OCCCCCCCC(C)O</smiles>

Figura 6. Ácido levulínico como uma plataforma para a síntese de vários intermediários valiosos

perigosos. ${ }^{32}$ Ela oferece técnicas e princípios que qualquer pesquisador pode e deve aplicar no desenvolvimento de biorrefinarias. O objetivo primordial da Química Verde combinado com uma biorrefinaria é produzir produtos químicos genuinamente verdes e sustentáveis. ${ }^{33} \mathrm{O}$ produto final deve ser não tóxico, degradável em produtos inócuos e com a geração de pequenas quantidades de resíduos.

As metodologias e técnicas empregadas pela Química Verde para atingir tais objetivos envolvem solventes não tóxicos e de pouca flamabilidade como $\mathrm{CO}_{2}$ supercrítico, líquidos iônicos, ultrassom, micro-ondas e principalmente fermentação de biomassas. ${ }^{34}$
Muitos polímeros naturais diretamente disponíveis pela biomassa apresentam potencial de gerarem produtos valiosos, através de modificações químicas e físicas. Entre estes se incluem amidos, celulose, hemicelulose, lignina, proteínas e lipídeos. A modificação de polímeros naturais é interessante uma vez que podem substituir polímeros derivados de fontes fósseis como plásticos e têxteis (Tabela 3 ).

\section{DIRETRIZES PARA A FUTURA BIORREFINARIA}

A biorrefinaria, da mesma forma do que ocorre com a refinaria de petróleo, deve ser baseada em processos que continuamente convertam matéria-prima em produtos mais sofisticados e com maior valor agregado. Deste modo, a biorrefinaria deve separar os componentes da biomassa e, através de uma sequência de vários processos, obter compostos puros de alta concentração (por exemplo, o etanol), ou ainda moléculas de elevadas concentrações e tendo funções parecidas (exemplo, misturas de alcanos nos combustíveis-FT).

\section{ALCOOLQUíMICA}

A Figura 7 resume o potencial de aplicação industrial do bioetanol gerado pela usina de açúcar, enquanto que a Figura 8 apresenta produtos oriundos da alcoolquímica e que podem vir a serem produzidos por uma biorrefinaria.

O grande diferencial dos produtos gerados a partir do bioetanol, e que já estão sendo utilizados pela indústria, é explorar o apelo que possuem atualmente junto aos consumidores, ou seja, poderem ser rotulados de verdes. Ilustra esta tendência do mercado, o polietileno verde que está sendo produzido no Brasil por empresas do porte da Braskem e da DowQuímica (ainda em fase de implantação). Para ser rotulado de verde, a Braskem teve de obter junto a empresas internacionais a certificação de que seu polietileno era oriundo de 


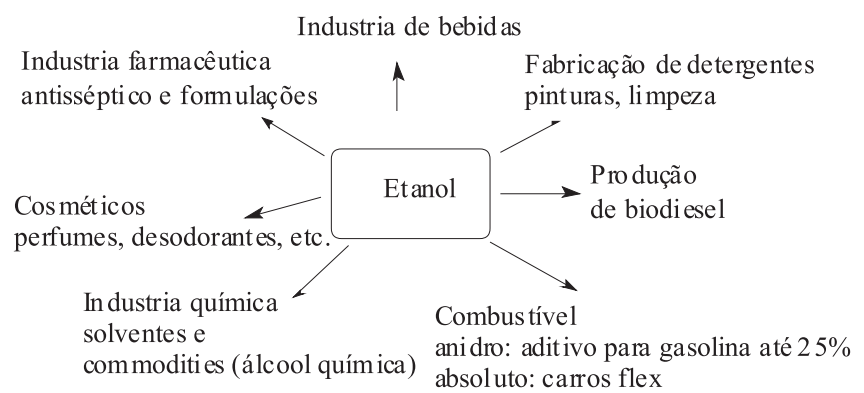

Figura 7. Usos do etanol pela indústria em geral

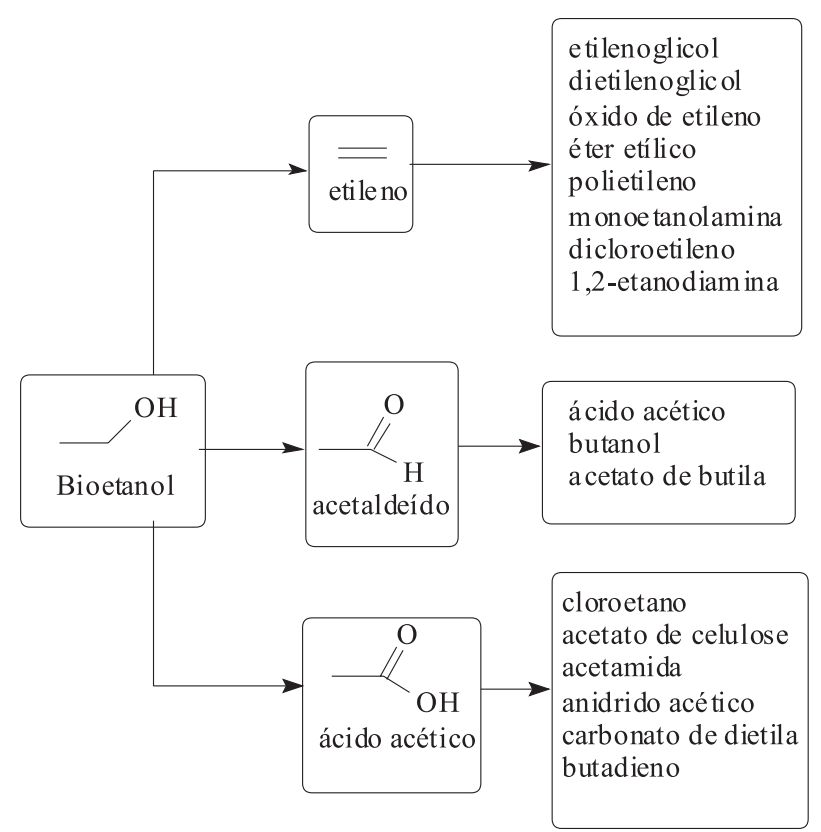

Figura 8. Alguns produtos oriundos da alcoolquímica que revelam o potencial da plataforma da futura biorrefinaria

carbono não fóssil. A Figura 8 apresenta alguns produtos que podem ser obtidos a partir do bioetanol e a partir destes vários outros podem ser produzidos. No Brasil o etanol é considerado como insumo da indústria química desde as primeiras décadas do século 20. As empresas Elekeiroz, Usina Colombina, Salgema, Rhodia, Victor Sence e Fábrica de Piquete (Ministério da Guerra) destacaram-se neste período pela produção de cloreto de etila, ácido acético, anidrido acético, acetato de celulose, éter etílico, butanol, acetato de butila, acetona, cloreto de vinila, etc. ${ }^{35}$ Nas décadas de 50 e 60 houve um crescimento significativo da indústria alcoolquímica. Nesse período, o eteno era gerado a partir da desidratação do etanol visando complementar a produção das refinarias de petróleo. Nos anos 70, esse panorama se modificou com o crescimento da indústria petroquímica, baseado na ampla disponibilidade de matéria-prima barata e na modernidade tecnológica.

O etileno é atualmente a substância de maior produção pela indústria petroquímica. A partir dele é gerado o polietileno e alguns compostos mais importantes da indústria petroquímica. A Figura 9 mostra esta plataforma que foi responsável pelo desenvolvimento da indústria química no início do século passado, e que agora pode ser produzida a partir do bioetanol.

Atualmente as usinas brasileiras produzem, em sua totalidade, apenas açúcar e etanol. Algumas poucas ainda produzem o plástico biodegradável $\mathrm{PHB}^{51}$ e outras tentam aproveitar o óleo fusel. $\mathrm{Na}$ Tabela 3 estão listadas as substâncias que potencialmente podem

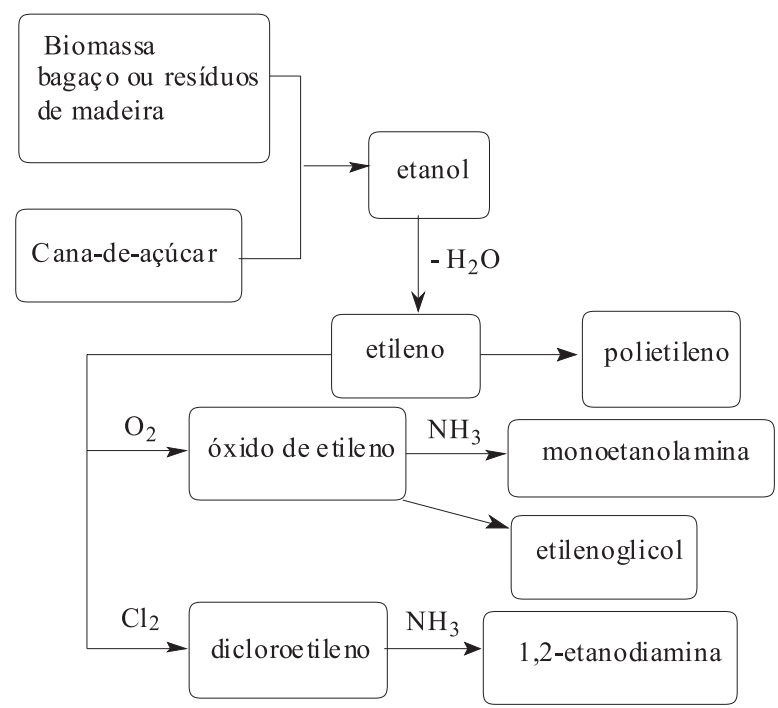

Figura 9. Produtos derivados da plataforma do bioetileno, produzido pela desidratação do bioetanol

Tabela 3. Produtos que potencialmente podem ser produzidos por uma biorrefinaria, tendo como material de partida a sacarose

\begin{tabular}{|c|c|c|c|}
\hline Entrada & Produto(s) & Processo & Ref. \\
\hline 1 & Glucose, Frutose & Invertase & \\
\hline \multirow[t]{3}{*}{2} & Acetona & Clostridium sp & 36 \\
\hline & Butanol & & \\
\hline & Etanol & & \\
\hline 3 & Etanol & Saccharomyces cerevisiae & 37 \\
\hline 4 & Ácido lático & Lactobacillus delbrueckii & 38 \\
\hline 5 & Ácido cítrico & Aspergillus niger & \\
\hline \multirow[t]{2}{*}{6} & Isopropanol Butanol & Clostridium acetobutylicum & 39 \\
\hline & Etanol & Clostridium beijerinckii & \\
\hline \multirow[t]{4}{*}{7} & Ácido acético & Propionibacterium & 41 \\
\hline & Ácido lático & acidipropionici & \\
\hline & Ácido succínico & & \\
\hline & Ácido propiônico & & \\
\hline 8 & glicerol & Saccharomyces cerevisiae & 42 \\
\hline & & engenherado & \\
\hline 9 & Ácido itacônico & Aspergillus terreus & 43 \\
\hline 10 & Ácido glucônico & Aspergillus niger & 44 \\
\hline \multirow[t]{2}{*}{11} & 1,3-propanodiol & Klebsiella oxytoca & 45 \\
\hline & 2,3-propanodiol & Klebssiella pneumoniae & 46 \\
\hline \multirow[t]{2}{*}{12} & Levan & Bacillus subitlis & 47 \\
\hline & Etanol & Zymomonas mobilisB & 48 \\
\hline 13 & PHB & Bacillus megaterrium & 49 \\
\hline 14 & Hidrogênio & Cat.de $\mathrm{Ru} \backslash$ líquido iônico & 50 \\
\hline
\end{tabular}

se produzidas a partir de açúcar de cana-de-açúcar. No passado, conforme já comentado, alguns produtos derivados do etanol foram produzidos em decorrência do incentivo governamental para a alcoolquímica. A mistura de solventes, acetona, butanol e etanol (ABE) foi produzida no Brasil por fermentação a partir do melaço (Tabela 3, entrada 2). Poderá voltar a ser produzida caso o barril de 
petróleo volte a ficar acima de US $\$ 100$ o barril. O butanol pode ser separado do $\mathrm{ABE}$ do qual é um constituinte majoritário, e é usado como aditivo para gasolina, da mesma forma que é empregado o etanol, ou transformado em produtos de maior valor agregado..$^{52} \mathrm{~A}$ produção do butanol por fermentação prosperou entre 1930 e 1950. A produção de $\mathrm{ABE}$ foi o segundo processo de fermentação mais antigo, sendo a produção de etanol a partir de levedura $S$. cerevisiae o primeiro. ${ }^{53}$ A rota metabólica do butanol de Clostridium requer 1 mol de glicose e 4 moles de NADH para produzir 1 mol de butanol. A mais alta concentração de butanol produzida por $C$. beijerinckii foi de $19,6 \mathrm{~g} \mathrm{~L}^{-1} \cdot{ }^{54}$ Uma metodologia interessante para extrair o butanol da mistura de $\mathrm{ABE}$ foi realizada usando-se biodiesel como solvente. Esta mistura biodiesel-butanol revelou um aumento do número de cetano do biodiesel que passou de 48 para $54 .{ }^{55}$ A síntese do ácido lático ou de lactatos de alquilas tem enorme apelo, considerando-se que são produtos versáteis e encontram aplicações nas indústrias química, alimentícia, farmacêutica e cosmética. ${ }^{56}$ Atualmente, tem havido crescente emprego como solventes ambientalmente amigáveis e como materiais de partida para a síntese do ácido polilático, um polímero biodegradável de ampla aplicação, ${ }^{57}$ e de poliésteres contendo lactato. ${ }^{58} \mathrm{O}$ processo comercial mais comum do ácido lático é baseado na fermentação de carboidratos (Tabela 3, entrada 4). ${ }^{59}$ A empresa PURAC de origem holandesa tem uma planta em operação em Campos (RJ) manufaturando ácido lático. Recentemente, foram descritos métodos de catálise química heterogênea empregando zeólitas para a produção de lactato de metila com elevadas conversões. ${ }^{60}$ Os mesmos micro-organismos que produzem $\mathrm{ABE}$ também são capazes de gerar IBE (isopropanol, butanol e etanol) dependendo das cepas empregadas. Entretanto, para a obtenção de maiores teores de isopropanol há necessidade do emprego de organismos geneticamente modificados. A rota metabólica para o isopropanol com Clostridium requer $1 \mathrm{~mol}$ de glicose para produzir $1 \mathrm{~mol}$ de isopropanol. ${ }^{61} \mathrm{~A}$ mais alta concentração de isopropanol obtido empregando C. acetobutylicon foi de $1,8 \mathrm{~g} \mathrm{~L}^{-1}$ (Tabela 3, entrada 6). O emprego de C. acetobutylicon modificado geneticamente e expressado em $E$. coli elevou a produção de isopropanol para 4,9 $\mathrm{g} \mathrm{L}^{-1}{ }^{62}$ Jojima e colaboradores ${ }^{63}$ também reconstruíram uma rota para isopropanol de Clostridium em E. coli atingindo uma produção de isopropanol de $13,6 \mathrm{~g} \mathrm{~L}^{-1}$. Este pode ser empregado como biocombustível para substituir a gasolina, além de poder ser desidratado, da mesma forma que o propanol, para formar propileno que é o monômero do polipropileno.

As propionibactérias são Gram-positivas, não formam esporos, anaeróbicas e têm a forma de bastonetes. São amplamente usadas na fabricação de queijos, na produção de vitamina $\mathrm{B}_{12}$, de compostos tetrapirrólicos e do ácido propiônico. Este último é um importante reagente usado na produção de plásticos de celulose, de herbicidas e de perfumes, além de ser um forte inibidor de mofos. Sais do ácido propiônico são usados como preservativos em alimentos. Atualmente, o ácido propiônico é produzido através de processos petroquímicos, mas pode ser gerado por processo fermentativo. A fermentação de melaço de cana-de-açúcar ou de glicose mediada por Propionibacterium acidipropionici fornece como produtos principais os ácidos propiônico, succínico e láctico (Tabela 3, entrada 7). ${ }^{64}$ Recentemente, a porcentagem do ácido propiônico, que é o produto majoritário, teve seu percentual aumentado atingindo 19,2 g L'-1, usando-se Propionibacterium freudenreichii CCTCC M207015, através do controle rigoroso do meio, iniciando-se com pH 6,5 e após 48 h diminuído para $\mathrm{pH} 6,0 .{ }^{65} \mathrm{~A}$ desvantagem da produção destes ácidos por fermentação é que geram grande quantidade de sais, que não possuem uma aplicação econômica. Recentemente, foi divulgado um processo integrado de produção de ácido succínico com E. coli AFP184 e de etanol pela levedura $S$. cerevisiae em fermentadores conjugados em série. ${ }^{66} \mathrm{O}$ gás carbônico produzido pela levedura é introduzido no reator da bactéria, o que provoca um incremento de 7 vezes na produção do ácido succínico. Este ácido encontra aplicações como aditivo de alimentos, em soldagens e como precursor de produtos químicos e farmacêuticos. ${ }^{67}$

O interesse pelo ácido cítrico (Tabela 3, entrada 5) decorre da sua intensa aplicação nas indústrias de laticínios, alimentos, bebidas, farmacêutica e química. Sua produção em 2008 atingiu cerca de 1,6 milhão de toneladas. ${ }^{68}$ São produzidas por fermentação com Aspergillus niger e atualmente muita ênfase tem sido notada com o emprego de conversão biológica de resíduos agroindustriais como bagaço de uva, de maçã, beterraba doce, banana, etc. ${ }^{69} \mathrm{O}$ ácido itacônico (ácido metilenosuccínico, (entrada 9, Tabela 3) é usado como monômero para formar polímeros como látex, resinas sintéticas, tintas, resinas acrílicas, além de acidulante em alimentos. A limitação atual de seu emprego decorre do alto custo. O micro-organismo mais usado é o fungo filamentoso Aspergillus terreus. ${ }^{70}$

\section{GLICEROQUÍMICA: GLICEROL, UMA IMPORTANTE MATÉRIA-PRIMA PARA A BIORREFINARIA}

O glicerol é uma matéria-prima potencialmente relevante para a biorrefinaria, disponível como subproduto da produção de biodiesel pela transesterificação de óleos vegetais ou gorduras animais. Para cada $9 \mathrm{~kg}$ de biodiesel produzido, cerca de $1 \mathrm{~kg}$ de glicerol bruto é formado. A produção microbiana de glicerol é conhecida há cerca de 150 anos. Durante a Segunda Guerra Mundial, o glicerol foi produzido a partir da fermentação de glicose por várias leveduras como Saccharomyces cerevisiae, Candida glycerinogenes, Candida magnólia, Pichia farinose, bactérias como Bacillus subtilis, e por algas como Dunaliella tertioleta..$^{71}$

Com o contínuo aumento da produção de biodiesel, o preço do glicerol tem decaído como resultado de sua acumulação. Como decorrência, a venda do glicerol tem se tornado o gargalo para o aumento da produção do biodiesel (estimada em 1,2 milhão de t em 2010) com custo de US\$ $0,33 / \mathrm{kg} .{ }^{72} \mathrm{O}$ atual preço do glicerol ainda é elevado para ser transformado em produtos primários importantes, cujos custos ainda são limitantes para competir com os daqueles originados da refinaria de petróleo. Mas ocorrendo queda acentuada do preço do glicerol, deverá acelerar sua transição a partir do seu atual estado da arte, como um intermediário avançado ou produto final para um material de partida de uma ampla família de compostos. O sucesso no desenvolvimento industrial destes produtos obtidos a partir do glicerol pode gerar uma significativa demanda desta commodity que poderá trazer reflexos no biodiesel, contribuindo para a diminuição de seu custo.

Recentemente, várias revisões bem estruturadas têm discutido o glicerol como fonte de matéria-prima para a indústria química, ${ }^{73}$ inclusive uma publicada em Química Nova ${ }^{74}$ Em decorrência, vamos considerar apenas aspectos mais recentes abordados na literatura, ou pouco enfatizados naquelas revisões. Com a contínua queda dos preços do glicerol em decorrência do aumento da oferta do biodiesel, o glicerol pode ser posicionado na biorrefinaria como um bloco de construção primário e renovável análogo daqueles da indústria petroquímica (metano, etileno, BTX, etc.). Na Figura 10, estão sumarizados os produtos que podem ser produzidos a partir do glicerol através de rotas químicas e biológicas. Atualmente, a Rhodia comercializa o solvente Augeo SL $191^{\circledR}$ (2,2-dimetil-4-hidroximetil-1,3-dioxolano, um cetal de glicerol) incolor, miscível com solventes orgânicos e com água, empregado em tintas, thinners, vernizes e couros.

Um número significativo de micro-organismos é capaz de crescer anaerobicamente em glicerol como única fonte de carbono, tais como Citrobacter freundii, Klebsiella pneumoniae, Clostridium pasteurianum, Clostridium butyricum, Enterobacter agglomerans, 


\section{Rota química}

Rota biológica

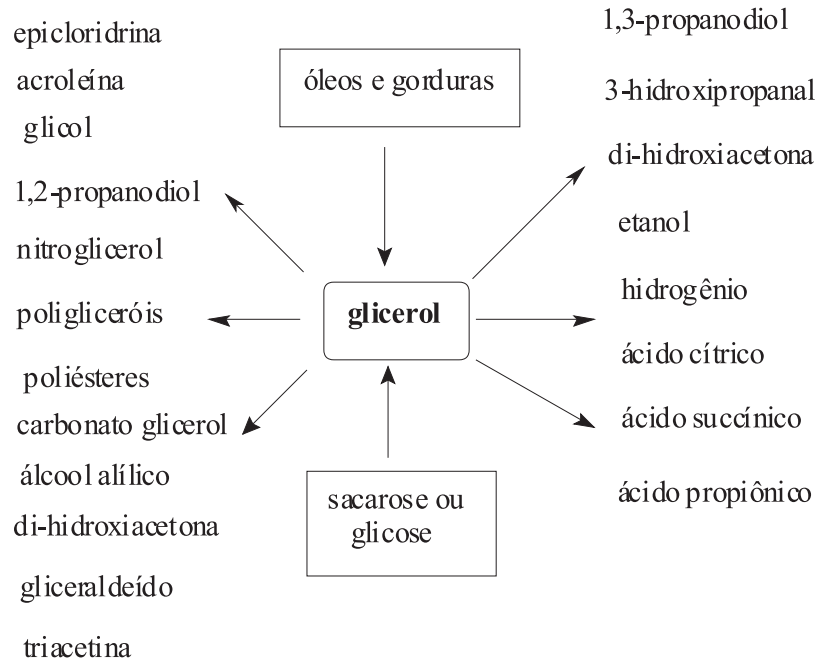

Figura 10. Produtos que podem ser produzidos a partir de glicerol através de rotas químicas e biológicas. Adaptado da ref.

Enterobacter aerogenes e Lactobacillus reuteri. ${ }^{75}$ A fermentação do glicerol, ao contrário da fermentação alcoólica da sacarose, fornece vários produtos cuja separação é trabalhosa. Por exemplo, com Propionibacterium acidipropionici, com Propinibacterium acnes, ou com Clostridium propionicum, o principal produto da fermentação é o ácido propiônico seguido de ácido succínico e ácido acético em menor proporção. ${ }^{76}$ As numerosas aplicações industriais do ácido propiônico têm provocado interesse crescente para o desenvolvimento de processo de produção biotecnológica baseado no glicerol como fonte renovável. ${ }^{77}$

A produção de etanol a partir da fermentação do glicerol tem recebido muita atenção nos últimos anos. O glicerol é não fermentável pela maioria dos micro-organismos, com exceção de um grupo de bactérias incluindo espécies como Bacillus, Clostridium, Enterobacter, Klebsiella e Lactobacillus. Recentemente, Gonzalez e colegas ${ }^{78}$ demonstraram que a fermentação anaeróbica de glicerol por Escherichia coli oferece uma nova plataforma para a produção de produtos químicos e combustíveis. Contudo, o custo de produção de etanol a partir de glicerol é quase $40 \%$ menor quando comparado com produção a partir do milho, em termos de demanda da matériaprima e custos operacionais. ${ }^{79}$ Estas constatações encorajaram a engenharia genética da $E$. coli para tornar mais eficiente a conversão fermentativa do glicerol a etanol e subprodutos. ${ }^{80}$ A levedura $S$. cerevisiae foi manipulada geneticamente visando aumentar a produção de etanol a partir de glicerol. Foram atingidas elevadas velocidades de conversão de glicerol através da simultânea expressão da glicerol desidrogenase (Gcy) e di-hidroxiacetona kinase (Dak), que são as enzimas responsáveis pela conversão do glicerol ao intermediário glicolítico di-hidroxiacetona fosfato. Como resultado, a produção de etanol em YPH499 (pGcyaDak) aumentou 3,4 vezes em relação à cepa selvagem, atingindo a produção de $2,4 \mathrm{~g} \mathrm{~L}^{-1}$ de etanol. ${ }^{81} \mathrm{Em}$ outra tentativa de aumentar a produção de etanol a partir de glicerol, o fermento Hansenula polymorpha foi modificado geneticamente, expressando os genes $p d c$ e $a d h B$ que codificam a piruvato descaboxilase e aldeído desidrogenase II da Zymomonas mobilis, para controlar a gliceraldeído-3-fosfato desidrogenase (GAPDH). O rendimento de etanol atingido foi de 2,74 $\mathrm{g} \mathrm{L}^{-1}$. Os mesmos autores conseguiram melhores resultados através da cepa recombinante que expressa os genes dhaD e dhaKLM da Klebsiella pneumoniae, codificando a glicerol desidrogenase e a desidroxiacetona kinase, respectivamente.
Desta maneira, obtiveram um rendimento de etanol de $3,1 \mathrm{~g} \mathrm{~L}^{-1}$.82 Até o presente momento, o melhor rendimento de etanol a partir da fermentação do glicerol foi conseguido pela expressão de $a d h A$ em E. coli CT1061, atingindo $15,4 \mathrm{~g} \mathrm{~L}^{-1}$ com uma produtividade de $0,34 \mathrm{~g} \mathrm{~L}^{-1} \mathrm{~h}^{-1} .83$

Um método eficiente foi descrito por Ellman e colaboradores para efetuar a 1,2-desoxigenação, envolvendo um inesperado mecanismo, foi encontrado para simples dióis e polióis (glicerol e eritritol) que resultou na conversão de grupos 1,2-di-hidroxilas para formar ligação $\mathrm{C}=\mathrm{C} .{ }^{84}$ Através deste método, o glicerol gerou o álcool alílico com $80 \%$ de rendimento após purificação por destilação (Esquema 2). O álcool alílico é um produto químico produzido em larga escala a partir do propeno, é usado na manufatura de vários polímeros e outros compostos alílicos e tem grande potencial como precursor do ácido 3-hidroxipropiônico, que é importante bloco de construção em processos usados em biorrefinaria. ${ }^{85}$

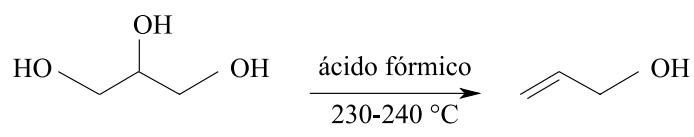

Esquema 2. Reação de desoxigenação do glicerol formando álcool alílico

Recentemente, Gu e Jérôme ${ }^{86}$ publicaram uma revisão mostrando que o glicerol pode ser usado com vantagem como um solvente sustentável e relevante para a Química Verde. O glicerol em sua forma pura tem sabor, é um liquido adocicado, incolor, sem odor e viscoso. É polar e prótico com constante dielétrica de $42,5\left(25^{\circ} \mathrm{C}\right)$, que o torna intermediário entre a água e um líquido iônico muito empregado como o hexafluorofosfato de 1-butil-3-metilimidazólio, sendo totalmente solúvel em água. A eficiência do glicerol como solvente pode ser avaliada em inúmeras reações, e como exemplo ilustramos no Esquema 3 a reação tipo $a z a$-Michel entre a $p$-anisidina e o acrilato de $n$-butila. ${ }^{87}$ Vários outros exemplos são mostrados na citada revisão de Gu e Jérôme.<smiles>COc1ccc(N)cc1</smiles><smiles>COc1ccc(NCCC(=O)c2ccccc2)cc1</smiles>

em glicerol: $82 \%$ de rendimento em 1,2-propanodiol: $30 \%$ de rendimento em água ou sem solvente: $<5 \%$ de rendimento em tolueno, DMF ou DMSO: nenhum produto

Esquema 3. Exemplo da eficiência do emprego do glicerol como solvente

Outro exemplo da eficiência do glicerol como solvente foi divulgado recentemente pelo grupo de Andrade $^{88}$ (Esquema 4). Foi observada uma sensível melhora no rendimento dos produtos quando glicerol foi empregado como cossolvente nas biorreduções de 2 -cloroacetofenona por Aspergillus terreus. É notável que elevados rendimentos dos alcoóis benzílicos fossem obtidos também em uma escala preparativa, mostrando o potencial uso do glicerol para a biocatálise.

A eterificação do glicerol é um processo promissor para oxigenar a utilização de combustíveis. O emprego destes éteres pode reduzir as emissões de materiais particulados, monóxido de carbono e compostos carbonílicos nos escapamentos de veículos. ${ }^{89}$ Mais importante, éteres de glicerol podem diminuir o ponto de névoa do diesel quando combinado com biodiesel. ${ }^{90}$ 
<smiles>CC(=O)c1ccccc1Cl</smiles>

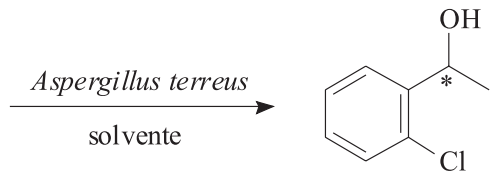

\begin{tabular}{lcc}
\hline solvente & Rendimento $(\%)$ & ee $(\%)$ \\
\hline PBS & 24 & 66 \\
PBS-glicerol (9:1) & 49 & 92 \\
PBS-glicerol (4:1) & 44 & $>99(S)$ \\
PBS-DMSO (9:1) & 50 & $>99(S)$ \\
PBS-CH ${ }_{3}$ CN (9:1) & 9 & $>99(S)$ \\
PBS-tolueno (9:1) & 4 & ------- \\
\hline
\end{tabular}

Esquema 4. Exemplo do uso do glicerol como co-solvente em uma reação de biocatálise

\section{A FOTOSSÍNTESE ARTIFICIAL}

É esperado que os combustíveis oriundos do Sol venham a ter uma importante contribuição para as necessidades futuras dos sistemas de energia. Estes combustíveis podem ser produzidos a partir de rotas diretas e indiretas. De maneira indireta é a conversão de carboidratos em etanol ou a de biomassa em biogás. Já as rotas diretas produzem combustíveis diretamente através de um sistema integrado, sem a intervenção de carreadores intermediários de energia. Exemplo deste último é o aproveitamento da energia solar para realizar a fotossíntese artificial. A fotossíntese em plantas verdes, algas e cianobactérias emprega energia solar para converter dióxido de carbono e água em combustível, via carboidratos ricos em energia. O objetivo da fotossíntese artificial não é competir com este processo, mas, em vez disso, aprender através dele a reproduzir os mesmos princípios em uma escala adequada para sistemas criados pelo homem. ${ }^{91}$

Um exemplo da aplicação de procedimentos semelhantes aos da fotossíntese artificial é a geração de combustíveis baseados em carbono formados pela redução de $\mathrm{CO}_{2}$, mas a catálise química envolvendo multielétrons torna o desafio bem difícil..$^{92} \mathrm{~A}$ produção de hidrogênio a partir de prótons emprega um processo de dois elétrons, o que torna o processo mais eficiente embora o armazenamento desse gás ainda seja problemático. A fotossíntese natural utiliza água como material de partida para fornecer elétrons na etapa redutiva do $\mathrm{CO}_{2}$. Contudo, o uso deste abundante substrato requer o controle da oxidação de multielétrons de duas moléculas de água para produzir oxigênio. Este processo é bem manipulado pela natureza e com boa eficiência, mas tem sido muito difícil reproduzir essa eficiência através da catálise homogênea artificial..$^{93}$

O armazenamento da energia solar através da fotossíntese é uma das mais notáveis façanhas da natureza. As tecnologias disponíveis exploram este processo para geração de energia processando partes da biomassa de plantas em etanol e biomassa de algas em biodiesel. Muito recentemente, possibilidades inéditas têm sido propostas para controlar e robustecer organismos fotossintéticos com novas habilidades de produzir diretamente biocombustíveis, desviando da necessidade de sintetizar todos os complexos produtos da biomassa. Uma maneira promissora para atingir este objetivo é redirecionar rotas do metabolismo de cianobactérias (ciclo de Calvin) para intermediários que levem diretamente a produtos de fermentação, desviando de passagens por carboidratos. Esta seria uma rota alternativa para produção de biocombustíveis direcionada pela luz a partir de $\mathrm{CO}_{2} \mathrm{e}$ $\mathrm{H}_{2} \mathrm{O}$, denominada pelos pesquisadores de fotoetanol (Figura 11). ${ }^{94} \mathrm{~A}$ vantagem desta proposta está na geração de biocombustíveis contornando a formação, por exemplo, da sacarose e gerando de maneira metabolicamente mais simples o etanol sem a necessidade de passar pela etapa agrícola, a maior restrição para a aceitação generalizada dos biocombustíveis. A biotecnologia de plantas proporciona ferramentas que podem permitir o rápido desenvolvimento de genótipos domesticados com crescimento rápido e característica composição otimizada para a produção de moléculas de estruturas definidas. ${ }^{95}$

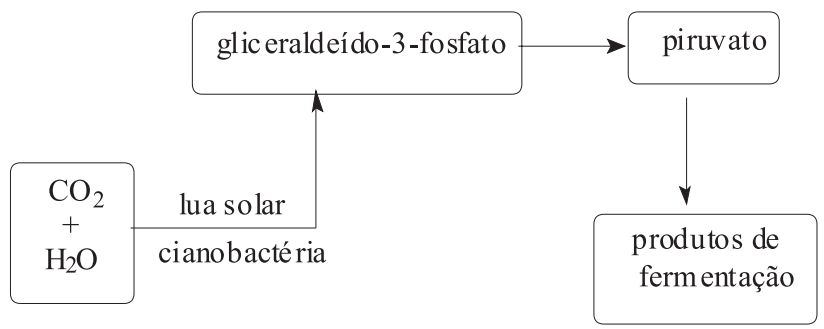

Figura 11. Representação esquemática simplificada do metabolismo de uma fotofermentação baseada na introdução de uma rota de fermentação

\section{BIO-HIDROCARBONETOS}

Considerável trabalho tem aparecido descrevendo novos processos para a produção bioquímica de hidrocarbonetos em uma biorrefinaria de açúcar. Tais processos deverão ser importantes para a expansão da biorrefinaria, uma vez que fornecerão uma interface direta entre a indústria de produtos biotecnológicos e a atual indústria petroquímica. $\mathrm{O}$ isopreno é um hidrocarboneto com um mercado mundial próximo de US\$ 2 bilhões. O precursor imediato do isopreno ocorre naturalmente em poli-isopropenoides, o difosfato de isopentenila (IPP). Foram descritas duas rotas levando ao IPP. ${ }^{96}$ O IPP é formado pela via mevalonato em eucariotos e arquea. Em certas bactérias, uma rota alternativa acontece através do fosfato de metileritritol. A Amyris desenvolveu uma levedura modificada por engenharia genética que fermenta açúcar para produzir -farneceno que, após ser hidrogenado, é chamado de Biofene ${ }^{\circledR}$, com características semelhantes ao diesel. Atualmente, ela opera uma planta piloto no Brasil e desde julho de 2010 faz teste com este diesel renovável na cidade de São Paulo com ônibus da SP Trans. Em 2008, a Genencor e a Goodyear anunciaram um programa em parceria para comercializar a manufatura de isopreno a partir de fontes bacterianas, a partir de 2012. Embora a Genencor não tenha revelado o processo exato em desenvolvimento, eles licenciaram a tecnologia patenteada pela Universidade de Colorado. ${ }^{97}$ Esta patente descreve o uso de espécies Bacillus (B. subtilis e B. amyloliquefaciens) para produzir elevado rendimento de isopreno. ${ }^{98} \mathrm{Em}$ março de 2009, a Genencor anunciou a entrega da primeira remessa para a Goodyear. ${ }^{99}$

Tem sido sugerida a produção de hidrocarbonetos de cadeias longas e de éteres lipídicos a partir de Botryococcus braunii, uma microalga verde. A biossíntese de hidrocarbonetos de botricocenos tem sido sugerida ocorrer através da formação de mevalonatos de isoprenoides. ${ }^{100} \mathrm{O}$ cultivo econômico em grande escala destas espécies não tem sido atingido, mas foram divulgados avanços em modificações genéticas destes materiais como uma possível alternativa. ${ }^{101}$

A bioprodução de hidrocarbonetos de cadeia longa foi reportada usando a bactéria isolada de lodos e identificada como Vibrio furnissii. Utilizando ácidos graxos de cadeia curta como material de partida, a produção extracelular de hidrocarbonetos de $\mathrm{C}_{15}$ a $\mathrm{C}_{24}$ foi atingida com rendimentos de $120 \%$ em relação à célula seca. ${ }^{102}$ Posteriormente, foi mostrado que $V$. furnissii M1 poderia produzir ampla variedade de hidrocarbonetos usando tanto ácidos orgânicos voláteis como carboidratos comumente encontrados em resíduos orgânicos. ${ }^{103} \mathrm{O}$ mecanismo de formação foi sugerido ocorrer por redução sucessiva do grupo carboxílico a aldeído, álcool e finalmente a alcano. ${ }^{104}$ Entretanto, tentativas recentes de reproduzir este trabalho falharam. ${ }^{105}$ 
Várias espécies Arthrobacter foram reportadas para sintetizar cadeias longas de alquenos. ${ }^{106}$

A produção de sorbitol por métodos bioquímicos tem sido investigada, embora a redução química da glicose produza mais de 500.000 t por ano. A fermentação da sacarose por Zymomonas mobilis produz sorbitol e ácido glucônico com rendimentos quase quantitativos. ${ }^{107}$ Mais recentemente, uma eficiente conversão de glicose a sorbitol com $97 \%$ de rendimento foi realizada usando células em repouso de Lactobacillus plantarum geneticamente modificadas. ${ }^{108}$ A conversão de sorbitol a alcanos foi reportada pela reforma em fase aquosa na presença de $\mathrm{Pt} / \mathrm{Al}_{2} \mathrm{O}_{3}$ formando hexano com $50 \%$ de seletividade. ${ }^{109} \mathrm{O}$ restante do açúcar é convertido em hidrocarbonetos gasosos (metano, etano, propano, etc.).

Se carboidratos pudessem ser convertidos em compostos com poucos grupos oxigenados que reagissem mais como derivados semelhantes aos do petróleo, poderiam suprir a indústria petroquímica com matéria-prima renovável. Duas publicações recentes por Bond et al. ${ }^{110}$ e Lange et al. ${ }^{111}$ sugerem que o ácido levulínico derivado por desidratação de glicose pode ser intermediário em processos de conversão catalítica para gerar ésteres do ácido valérico. ${ }^{112} \mathrm{~A}$ transformação da $\gamma$-valerolactona na presença de $\mathrm{Pb} / \mathrm{Nb}_{2} \mathrm{O}_{6}$ gera como intermediários alquenos que sofrem posterior oligomerização para formar alcanos $\mathrm{C}_{9}-\mathrm{C}_{16}$ com potencial de serem empregados como combustíveis líquidos tipo diesel. ${ }^{113}$

\section{CONCLUSÕES}

A Assessoria de Gestão Estratégica (AGE) do Ministério da Agricultura, Pecuária e Abastecimento (MAPA) divulgou um extenso estudo intitulado "Projeções do Agronegócio Brasil: 2009/2010 a 2019/2020", que prevê o crescimento da produção de açúcar (cerca de 46,7 milhões de t) e de etanol (62,9 bilhões de L), mais do que o dobro da produção 2008/2009, de 27,7 bilhões de L. Outro produto com previsão elevada de crescimento é o óleo de soja, que é a principal matéria-prima da cadeia produtiva de oleoquímicos a ser utilizada na produção do biodiesel. ${ }^{114}$ Estes números revelam a importância que está reservada ao Brasil no crescimento dos combustíveis de primeira geração para a corrente década, e reflete os incentivos de financiamentos que estão disponíveis atualmente para a Academia e empresas em geral. A previsão de aumento de produção de açúcar e álcool implica também no correspondente aumento de disponibilidade do bagaço e de palha de cana-de-açúcar. Em decorrência, a FINEP e a FAPESP criaram programas de incentivo para a produção de bioetanol via enzimática a partir da biomassa da cana-de-açúcar. ${ }^{15}$

A biorrefinaria baseada em lignocelulose poderá ter sucesso no futuro através de combinação de diferentes tecnologias e estratégias de processamento da biomassa para a produção de diversos combustíveis e produtos químicos. Os desafios a serem superados devem ser baseados em: desenvolvimento continuado de estratégias robustas para a produção de plataformas químicas de moléculas, tais como ácido levulínico e -valerolactona; aplicações de plataformas químicas para a produção de especialidades químicas e hidrocarbonetos; estratégias simples para a desconstrução de biomassa, tais como pirólise rápida; métodos para a combinação sinergística de métodos hidrolíticos e termoquímicos em biorrefinarias totalmente integradas; implementação de processos em cascata combinados com o desenvolvimento de esquemas simples de separação e purificação de produtos e, metodologias para a utilização de lignina.

Para cada tipo de biomassa deverá ser empregada uma estratégia específica. A hidrólise de biomassa é mais adequada para a produção de moléculas definidas. Assim, o ácido levulínico e a -valerolactona são prontamente preparadas por hidrólise da biomassa e são blocos de construção de moléculas mais complexas. Entretanto, estratégias hidrolíticas não são adequadas para todos os tipos de biomassa, como aquelas ricas em triglicéridos ou lignina. Frações de baixo conteúdo de carboidratos são mais adequadas para pirólise e gaseificação. Por outro lado, frações enriquecidas em carboidratos são preferidas pelos métodos biológicos para geração de alcoóis e especialidades químicas em uma biorrefinaria totalmente integrada. O preço do barril de petróleo acima de US\$ 100 é o maior incentivo para a utilização de biomassa substituir os produtos das atuais refinarias de petróleo.

Como conclusão final, enumeramos alternativas recentes para o aproveitamento de biomassas amplamente disponíveis em nosso país para a transformação em produtos químicos e, em particular, em combustíveis renováveis. Mostramos que as alternativas são inúmeras principalmente para os produtos da alcoolquímica. As usinas de açúcar e álcool estão deixando de serem propriedades familiares para se transformarem em grandes sociedades em poder de conglomerados com reconhecida competência na produção de produtos químicos industriais. Os recursos e a bagagem tecnológica que possuem permite visualizar para um futuro não distante a transformação das usinas em biorrefinarias, copiando o atual sucesso das refinarias de petróleo para fornecer produtos químicos em geral.

\section{AGRADECIMENTOS}

Ao apoio financeiro das entidades de fomento FAPESP e CNPq, aos colegas do IQ-UNICAMP que leram e deram importantes sugestões durante a elaboração do manuscrito e em especial a A. Morschbacker da Braskem.

\section{REFERÊNCIAS E NOTAS}

1. Furtado, C.; Formação Econômica do Brasil, Ed. Nacional: São Paulo, $8^{\mathrm{a}} \mathrm{ed}, 1968$.

2. Neves, M. F.; Trombin, V. G.; Consoli, M. Em Etanol e Eletricidade: a cana-de-açúcar no futuro da matriz energética; de Souza, E. L. L.; Macedo, I. de C., eds.; Luc Projetos de Comunicação Ltda: São Paulo, 2010, cap. 1, p. 20; www.única.com.br/Downloads/ estudosmatrizenergetica/livro-etanol-bioeletricidde.pdf, acessada em Novembro 2010.

3. Bajay, S. V.; Nogueira, L. A. H.; de Souza, F. J. R. Em ref. 2, cap. 9, p. 268.

4. Jank, M. S. Em ref. 2, p. 10.

5. Ref. 3, pág. 280.

6. Pires, A.; Schechtman, R. Em ref. 2, cap. 7, p. 206.

7. Foi publicado recentemente amplo estudo abordando vários aspectos (agronômicos, engenharia de produção de etanol, de eletricidade e de biodiesel) da produção de bioetanol que não são discutidos nesta revisão: Cortez, L. A. B.; Bioetanol de cana-de-açúcar, Ed. E. Blucher: São Paulo, 2010.

8. Lima, U. de A.; Basso, L. C.; Amorin, H. V. Em Biotecnolgia IndustriaL; Lima, U. de A.; Aquarone, E.; Borzani, W.; Schmidell, W., eds.; Ed. Edgard Blucher Ltda: São Paulo, 2001, vol. 3, cap. 1.

9. Farina, E.; Viegas, C.; Pereda, P.; Garcia, C. Em ref. 2, cap. 8, p. 234.

10. Conceito de biorrefinaria do National Renewable Energy Laboratory (NREL) dos Estados Unidos e disponível em http://www.nrel.gov/ biomass/biorefinary.html, acessada em Março 2011.

11. Para entender os problemas em definir sustentabilidade, veja: Sheehan, J. J.; Curr. Opin. Biotechnol. 2009, 20, 318.

12. Gasol, C. M.; Gabarrell, X.; Antón, A.; Rigola, M.; Carrasco, J.; Ciria, P.; Biomas Bioenergy 2007, 31, 543; Quintero, J. A.; Montoya, M. I.; Sanches, O. J.; Giraldo, O. H.; Cardona, C. A.; Energy 2008, 33, 385.

13. Kim, S.; Dale, B. E.; Biomass Bioenergy 2005, 29, 426; Blottnitz, H.; Curran, M. A.; J. Clean Prod. 2007, 15, 607

14. Larson, E. D.; Energy for Sustentainable Development 2006, 10, 109. 
15. Goldemberg, J.; Guardabassi, P.; Biofuels, Bioprod. Bioref. 2010, 4, 17.

16. Marris, E.; Nature 2006, 244, 670; Lange, J. P.; Biofuels, Bioprod. Bioref. 2007, 1, 39.

17. Cherubini, F.; Bird, N.; Cowie, A.; Jungmeier, G.; Schlamadinger, B.; Woess-Gallasch, S.; Resour. Conserv. Recycling 2009, 53, 434.

18. Searcy, E.; Flynn, P. C.; Int. J. Green Energy 2008, 5, 423; Fleming, J. S.; Habibi, S.; MacLean, H. L.; Transp. Res. Part D: Transport Environment 2006, 11, 146.

19. Cherubini, F.; Biofuels, Bioprod. Biorefin. 2009, 3, 534.

20. Cherubini, F.; Energy Conversion Management 2010, 51, 1412; Cherubini, F.; Stromman, A. H.; Energy Fuels 2010, 24, 2657.

21. Clarck, J. H.; Deswarte, F. D. I.; Farmer, T. J.; Biofuels, Bioprod. Bioref. 2009, 3, 72 .

22. Dale, B. E.; Kim, S. Em Biorefineries- Industrial Process and Products; Kamm, B.; Gruber, P. R.; Kamm, M., eds.; Wiley-VCH: Weinheim, 2006, vol. 1 .

23. Lange, J.-P.; Biofuels, Bioprod. Biorefin. 2007, 1, 39.

24. Para uma revisão recente sobre hidrólise enzimática de biomassa veja: Ogeda, T. L.; Petri, D. F. S.; Quim. Nova 2010, 33, 1549.

25. Para revisão recente veja: Alonsi, D. M.; Bond, J. Q.; Dumesic, J. A.; Green Chem. 2010, 12, 1493.

26. Hamelinck, C. N.; van Hooijdonk, G.; Haaij, A. P. C.; Biomass Bioenergy 2005, 28, 384; Cardona Alzate, C. A.; Sánchez Toro, O. J.; Energy 2006, 31, 2447.

27. Bridgwater, A. V.; Peacocke, G. V. C.; Renew. Sustain. Energy Rev. 2000, 4,1 .

28. Li, X. T.; Grace, J. R.; Lim, C. J.; Watkinson, A. P.; Che, H. P.; Kim, J R.; Biomass, Bioenergy 2004, 26, 171; Zhang, Q.; Chang, J.; Wang, T.; $\mathrm{Xu}, \mathrm{Y}$; Energy Convers. Manage. 2007, 48, 87.

29. Wepy, T.; Pedersen, G.; Bulk Chemicals from Biomass, US Department of Energy: Washington, 2005, vol. 1.

30. Clarck, J. H.; Deswarte, F. E. I.; Introduction to Chemicals from Biomass, Wiley VCH: Weinheim, 2008.

31. Bozell, J. J.; Moens, L.; Elliot, D. C.; Wang, Y.; Neuenschwander, C. G.; Fitzpatrick, S. W.; Bilski, R. J.; Jarnefeld, J. L.; Resour. Conserv. Recycling 2000, 28, 227.

32. Sheldon, R. A.; Chem. Comunn. 2008, 3352.

33. Sheldon, R. A.; Arends, I.; Hanefeld, U.; Green Chemistry and Catalysis, Wiley-VCH: Weinheim, 2007.

34. Gronnow, M. J.; White, R. J.; Clarck, J. H.; Macquarrie, D. J.; Org. Process Res. Dev. 2005, 9, 516.

35. Centro de Gestão e Estudos Estratégicos (CGEE); Química Verde no Brasil - 2010-2030; Brasília, DF, 2010; http://cgee.org.br, acessada em Novembro 2010

36. Gheshaghi, R.; Scharer, J. M.; Moo-Young, M.; Chou, C. P.; Biotechnol Adv. 2009, 27, 764; Zheng, Y.-N.; Li, L.-Z.; Xian, M.; Ma, Y.J.; Yang, J. M.; Xu, X.; He, D.-Z.; J. Ind. Microbiol. Biotechnol. 2009, 36, 1127; Qureshi, N.; Saha, B. C.; Dien, B.; Hector, R. E.; Cotta, M. A.; Biomass Bioenergy 2010, 34, 559.

37. Kosaric, N. Em Biotechnology; Rehm, H-J.; Reed, G., eds; VCH: Weinheim, 1993, vol. 6, cap. 4, p. 121.

38. Coszach, P.; Bogaert, J.-C.; Mariage, P.-A.; Eur. Pat. Appl. 1953234 2008.

39. Chen, J. S.; Hiu, S. F.; Biotechnol. Lett. 1986, 8, 371.

40. Krouwel, P. G.; Groot, W. J.; Kossen, N. F. W.; Biotechnol. Bioeng. 1983, 25, 2299.

41. Barbirato, F.; Chedaille, D.; Bories, A.; Appl. Microbiol. Biotechnol. 1997, 47, 441; Himmi, E. H.; Bories, A.; Boussaid, A.; Hassani, L.; Appl. Microbiol. Biotechnol. 2000, 53, 435; Suwannakham, S.; Yang, S.-T.; Biotechnol. Bioeng. 2005, 91, 325.

42. Overkamp, K. M.; Bakker, B. M.; Kotter, P.; Luttik, M. A. H.; van Dijken, J. P.; Pronk, J. T.; Appl. Environ. Microbiol. 2002, 68, 2814; Modig, T.; Granath, K.; Adler, L.; Lidén, G.; Appl. Microbiol. Biotech- nol. 2007, 75, 289; Geertman, J.-M. A.; van Dijken, J. P.; Pronk, J. T.; FEMS Yeast Res. 2006, 6, 1193.

43. Neubel, R. D.; Ratajac, E. J.; US pat. 3,044.991 1962; Batti, M. A.; Schwvwiger, L. B.; US. Pat. 3,078.217 1964.

44. Molliard, M.; C. R. Hebd. Seances Acad. Sci. 1922, 174, 881.

45. Yang, G.; Tian, J.; Appl. Microbiol. Biotechnol. 2007, 73, 1017.

46. Zhang, D.; Wang, W.; Xiu, Z.; Biotechnol. Lett. 2006, 28, 1755; Liu, H.J.; Zhang, D.-J.; Xu, Y.-H.; Mu, Y.; Sun, Y.-Q.; Xiu, Z.-L.; Biotechnol. Lett. 2007, 29, 1281.

47. Shih, I.-L.; Chen, L.-D.; Wang, T. C.; Wu, J.-Y.; Liaw, K.-Y.; Green Chem. 2010, 12, 1242.

48. Millichip, R. J.; Doelle, H. W.; Process Biochem. 1989, 24, 141.

49. Kulpreecha, S.; Boonruangthavorn, A.; Meksiriporn, B.; Thongchul, N.; J. Biosci. Bioeng. 2009, 107, 240.

50. Taccardi, N.; Assenbaum, D.; Berger, M. E. M.; Bösmann, A.; Enzenberger, F.; Wölfel, R.; Neuendorf, S.; Goeke, V.; Schödel, N.; Maass, H. -J.; Kistenmacher, H.; Wasserscheid, P.; Green Chem. 2010, 12, 1150.

51. Para uma revisão sobre a preparação e usos de PHB veja: Pandian, S. R.; Deepak, V.; Kalishwaralal, K.; Rameshkumar, N.; Jeyaraj, M.; Gurunathan, S.; Bioresour. Technol. 2009, 101, 705.

52. Durre, P.; Biotechnol. J. 2007, 2, 1525; Durre, P.; Bohringer, M.; Nakottel, S.; Schaffer, S.; Thormann, K.; Zickner, B.; J. Mol. Microbiol. Biotechnol. 2002, 4, 295.

53. Jones, D. T.; Woods, D. R.; Microbiol. Rev. 1986, 50, 484.

54. Qureshi, N.; Blaschek, H. P.; Biotechnol. Prog. 1999, 15, 594.

55. Li, Q.; Cai, H.; Hao, B.; Zhang, C.; Yu, Z.; Zhou, S.; Chenjuan, L.; Appl. Biochem. Biotechnol. 2010, 162, 2381.

56. Corma, A.; Iborra, S.; Velty, A.; Chem. Rev. 2007, 107, 2411

57. Dumright, R. E.; Gruber, P. R.; Henton, D. E.; Adv. Mater. 2000, 12, 11841; Vink, E. T. H.; Rábago, K. R.; Glassner, D. A.; Springs, B.; O`Connor, R. P.; Kolstad, J.; Gruber, P. R.; Macromol. Biosci. 2004, 4, 551 .

58. Matsumoto, K.; Taguchi, S.; Appl. Microbiol. Biotechnol. 2010, 85, 921.

59. Singhvi, M.; Joshi, D.; Adsul, M.; Varma, A.; Gokhale, D.; Green Chem. 2010, 12, 1106.

60. Holm, M. S.; Saravanamurugan, S.; Taarning, E.; Science 2010, 328, 602; Pescarmona, P. P.; Janssen, K. P. F.; Delaet, C.; Stroobants, C.; Houthoofd, K.; Philippaerts, A.; de Jonghe, C.; Paul, J. S.; Jacobs, P. A.; Sels, B. F.; Green Chem. 2010, 12, 1083.

61. Peralta-Yahya, P.; Keasling, J. D.; Biotechnol. J. 2010, 5, 142.

62. Hanai, T.; Atsumi, S.; Liao, J. C.; Appl. Environ. Microbiol. 2007, 73, 7814.

63. Jojima, T.; Inui, M.; Yukawa, H.; Appl. Microbiol. Biotechnol. 2008, 77, 1219.

64. Coral, J.; Kaaarp, S. G.; Vandenberghe, L. P. de S.; Parada, J. L.; Pandey, A.; Soccol, C. R.; Appl. Biochem. Biotechnol. 2008, 151, 333.

65. Feng, X.; Xu, H.; Yao, J.; Li, S.; Zhu, H.; Ouyang, P.; Appl. Biochem. Biotechnol. 2010, 160, 343 .

66. Nghiem, N. P.; Hicks, K. B.; Johnston, D. B.; Appl. Biochem. Biotechnol. 2010, 162, 1915.

67. Fumagali, C. Em Kirk-Othmer Encyclopedia of Chemical Technology; Kroschwitz, J. I.; Howe-Grant, M., eds.; Wiley: New York, 1997, vol. 22, p. 1072.

68. Sauer, M.; Porro, D.; Mattanovich, D.; Branduardi, P.; Trends Biotechnol. 2008, 226, 100.

69. Karthikeyan, A.; Sivakumar, N.; Bioresour.Technol. 2010, 101, 5552.

70. Kanamasa, S.; Dwiarti, L.; Okabe, M.; Park, E. Y.; Appl. Microbiol. Biotechnol. 2008, 80, 223.

71. Para uma revisão sobre a produção de glicerol por fermentação veja: Wang, Z. X.; Zhuge, J.; Fang, H.; Prior, P. A.; Biotechnol. Adv. 2001, $19,201$.

72. Ott, L.; Bicker, M.; Vogel, H.; Green Chem. 2006, 8, 214.

73. Zheng, Y.; Chem, X.; Shen, Y.; Chem. Rev. 2008, 108, 5253. 
74. Mota, C. J. A.; da Silva, C. X. A.; Gonçalves, V. L. C.; Quim. Nova 2009, 32, 639.

75. Para uma revisão recente sobre o uso de glicerol como única fonte de carbono e a descrição das rotas metabólicas associadas veja: da Silva, G. P.; Mack, M.; Contiero, J.; Biotechnol. Adv. 2009, 27, 30.

76. Barbirato, F.; Chedaille, D.; Bories, A.; Appl. Microbiol. Biotechnol. 1997, 47, 441.

77. Himmi, E. H.; Bories, A.; Boussaid, A.; Hassani, L.; Appl. Microbiol. Biotechnol. 2000, 53, 435.

78. Ganzalez, R.; Murarka, A.; Dharmaddi, Y.; Yazdani, S. S.; Metab. Eng. 2008, 10, 234; Dharmadi, Y.; Murarka, A.; Gonzalez, R.; Biotechnol. Bioeng. 2006, 94, 821.

79. Yasdani, S. S.; Gonzáles, R.; Curr. Opin. Biotechnol. 2007, 18, 213.

80. Yasdani, S. S.; Gonzalez, R.; Metab. Eng. 2008, 10, 340; Durnin, G.; Clomburg, J.; Yeates, Z.; Alvarez, P. J.; Zygourakis, K.; Campbell, P.; Gonzalez, R.; Biotechnol. Bioeng. 2009, 103, 148.

81. Kyung, O. K.; Kim, S. W.; Han, S. O.; Bioresour. Technol. 2010, 101, 4157.

82. Hong, W.-K.; Kim, C.-H.; Heo, S-Y.; Luo, L. H.; Oh, B.-R.; Seo, J.-W.; Biotechnol. Lett. 2010, 32, 1077.

83. Nikel, P. I.; Ramirez, M. C.; Pettinari, M. J.; Méndez, B. S.; Galvagno, M. A.; J. Appl. Microbiol. 2010, 109, 492.

84. Arceo, E.; Marsden, P.; Bergman, R. G.; Ellman, J. A.; Chem. Comunn. 2009, 3357.

85. Della, C. P.; Falletta, E.; Rossi, M.; ChemSusChem 2009, $2,57$.

86. Gu, Y.; Jérôme, F.; Green Chem. 2010, 12, 1127.

87. Gu, Y.; Barrault, J.; Jérôme, F.; Adv. Synth. Catal. 2008, 350, 2007.

88. Andrade, L. H.; Piovaan, L.; Pasquini, M. D.; Tetrahedron: Asymmetry 2009, 20, 1521.

89. Kesling, H. S.; Kara, L. J.; Liotta, F. J.; US pat. 5,308,365 1994.

90. Noureddini, H.; US pat. 6,015,440 2000; Kiatkittpong, W.; Suwanmanee, S.; Laosiripojana, N.; Prasenthdam, P.; Assabumrungrat, S.; Fuel Process. Technol. 2010, 91, 456.

91. Gust, D.; Moore, T. A.; Moore, A. L.; Acc. Chem. Res. 2009, 42, 1890.

92. Dau, H.; Zaharieva, I.; Acc. Chem. Res. 2009, 42, 1861.

93. Dismukes, G. C.; Brimblecombe, R.; Felton, G. A. N.; Pryadun, R. S.; Sheats, J. E.; Spiccia, L.; Swiegers, G. F.; Acc. Chem. Res. 2009, 42, 1935; Romain, S.; Vigara, L.; Llobet, A.; Acc. Chem. Res. 2009, 42, 1944.

94. Hellingwerf, K.; Teixeira de Mattos, M. J.; J. Biotechnol. 2009, 142, 87.

95. Henry, R. J.; Plant Biotechnol. J. 2010, 8, 288.

96. Kuzuyama, T.; Seto, H.; Nat. Prod. Rep. 2003, 20, 171; Kuzuyama, T.;

Biosci. Biotechnol. Biochem. 2002, 66, 1619.
97. Fall, R.; Kuzma, J.; Nemecek-Marshall; US pat. 5,849,970 1998, para a Universidade de Colorado.

98. Kuzma, J.; Nemecek-Marshall, M.; Pollock, W. H.; Fall, R.; Curr. Microbiol. 1995, 30, 97.

99. http://www.danisco.com/cms/connect/corporate/media+relations/news/ frontpage/pressrelease_453_em.htm, acessada em Dezembro 2010.

100. Metzger, P.; Largeau, C.; Appl. Microbiol. Biotechnol. 2005, 66, 486.

101. Fortman, J. L.; Chhabra, S.; Mukhopadhyay, A.; Chou, H.; Lee, T. S.; Steen, E.; Keasling, J. D.; Trends Biotechnol. 2008, 26, 375.

102. Park, M.-O.; Tanabe, K.; Hirata, K.; Miyamoto, K.; Appl. Microbiol. Biotechnol. 2001, 56, 448.

103. Park, M.-O; Heguri, K.; Hirata, K.; Miyamoto, K.; J. Appl. Microbiol. 2005, $98,324$.

104. Park, M.-O; J. Bacteriol. 2005, 187, 1426.

105. Wackett, L. P.; Frias, J. A.; Seffernick, J. L.; Sukovich, D.J.; Cameron, S. M.; Appl. Environ. Microbiol. 2007, 73, 7192.

106. Frias, J. A.; Richman, J. E.; Wackett, L. P.; Appl. Environ. Microbiol. 2009, 75, 1774.

107. Silveira, M. M.; Jonas, R.; Appl. Microbiol. Biotechnol. 2002, 59, 400.

108. Ladero, V.; Ramos, A.; Wiersma, A.; Goffin, P.; Schanck,, A.; Kleerebezem, M.; Hugenholtz, J.; Smid, E. J.; Hols, P.; Appl. Environ. Microbiol. 2007, 73, 1864.

109. Huber, G. W.; Dumesic, J. A.; Catal. Today 2006, 111, 119.

110. Bond, J. Q.; Alonso, D. M.; Wang, D.; West, R. M.; Dumesic, J. A.; Science 2010, 327, 1110.

111. Lange, J.-P.; Price, R.; Ayoub, P. M.; Louis, J.; Petrus, L.; Clarke, L.; Gosselinl, H.; Angew. Chem., Int. Ed. 2010, 49, 4479.

112. Para uma revisão crítica veja: Bozell, J. J.; Science 2010, 329, 522.

113. Alonso, D. M.; Bond, J. Q.; Serrano-Ruiz, J. C.; Dumesic, J. A.; Green Chem. 2010, 12, 992.

114. Ministério da Agricultura, Pecuária e Abastecimento, Assessoria de Gestão Estratégica (AGE), Projeções do Agronegócio - Brasil 2000/2010 a 2019/2020; Brasília, 2010; www.agricultura.gov.br, acessada em Novembro 2010.

115. Para uma revisão recente sobre as perspectivas brasileiras do bioetanol obtido a partir de lignoceluloses veja: Soccol, C. R.; Vandenberghe, L. P.; Medeiros, A. B. P.; Buckeridge, M.; Ramos, L. P.; Pitarelo, A. P.; Ferreira-Leitão, V.; Gottschalk, L. M. F.; Ferrara, M. A.; Bom, E. P. S.; de Moraes, L. M. P.; Araújo, J. A.; Torres, F. A. G.; BioresourTechnol. 2010, 101, 4820 . 